\title{
Chromatin modifications and DNA repair: beyond double-strand breaks
}

\author{
Nealia C. M. House ${ }^{1}$, Melissa R. Koch ${ }^{1}$ and Catherine H. Freudenreich ${ }^{1,2}{ }^{*}$ \\ ' Department of Biology, Tufts University, Medford, MA, USA \\ 2 Program in Genetics, Sackler School of Graduate Biomedical Sciences, Tufts University, Boston, MA, USA
}

\section{Edited by:}

Antonio Porro, University of Zurich, Switzerland

\section{Reviewed by:}

Alessandra Montecucco, Consiglio

Nazionale delle Ricerche, Italy Velibor Savic, Brighton-Sussex

Medical School, UK

*Correspondence:

Catherine H. Freudenreich, Department of Biology, Tufts University, 200 Boston Avenue, Suite 4700 Medford, MA 02155, USA

e-mail: catherine.freudenreich@tufts.edu

DNA repair must take place in the context of chromatin, and chromatin modifications and DNA repair are intimately linked. The study of double-strand break repair has revealed numerous histone modifications that occur after induction of a DSB, and modification of the repair factors themselves can also occur. In some cases the function of the modification is at least partially understood, but in many cases it is not yet clear. Although DSB repair is a crucial activity for cell survival, DSBs account for only a small percentage of the DNA lesions that occur over the lifetime of a cell. Repair of single-strand gaps, nicks, stalled forks, alternative DNA structures, and base lesions must also occur in a chromatin context. There is increasing evidence that these repair pathways are also regulated by histone modifications and chromatin remodeling. In this review, we will summarize the current state of knowledge of chromatin modifications that occur during non-DSB repair, highlighting similarities and differences to DSB repair as well as remaining questions.

Keywords: histone modification, chromatin remodeler, DNA structure, sister chromatid recombination, gap repair, stalled replication fork, excision repair, mismatch repair

\section{INTRODUCTION}

Assaults to the genome are common throughout the lifetime of a cell and DNA damage can occur by endogenous factors, such as reactive oxygen species, base mismatches, and alternative (non- $\mathrm{B}$ form) DNA structures, or exogenous factors, such as ultraviolet (UV) radiation and environmental toxins. At the occurrence of a DNA lesion, the cell will initiate repair to protect the integrity of the genetic material. As the genome is condensed into chromatin, repair must work within the context of the chromatin structure to access and repair the damaged DNA.

One mechanism to alter chromatin structure is to modify histone residues by the addition of chemical groups such as a phosphate, acetyl, or one or more methyl groups. Small peptides such as ubiquitin and SUMO can also be added to lysine residues. These histone modifications can change nucleosomeDNA or nucleosome-nucleosome interactions to either open or condense the chromatin structure. For example, acetylation of histone $\mathrm{H} 4$ at lysine $16(\mathrm{H} 4 \mathrm{~K} 16 \mathrm{ac})$ reduces the interaction between the $\mathrm{H} 4$ tail and the $\mathrm{H} 2 \mathrm{~A}$ acidic pocket, inhibiting higher-order nucleosomal folding and resulting in a more open chromatin confirmation (Shogren-Knaak et al., 2006; Robinson et al., 2008). Alternatively, histone modifications that occur upon DNA damage can alter the interaction of non-histone proteins with chromatin to facilitate direct recruitment of repair factors and contribute to checkpoint initiation and termination (Humpal et al., 2009). ATP-dependent chromatin remodelers are also actively altering the chromatin landscape to promote repair (Seeber et al., 2013). Remodelers can slide nucleosomes, evict whole or partial nucleosomes, or alter the interaction between nucleosomes and DNA (Seeber etal., 2013). Still, in many cases, the details of how histone modifications and chromatin remodeling are affecting the formation, or progression of repair intermediates is not well understood. These intermediates include replication fork stabilization, strand resection, gap filling, and strand invasion or extension. The efficiency of formation or resolution of repair intermediates could ultimately dictate repair-pathway choice.

DNA double-strand breaks (DSBs) are considered to be the most lethal type of DNA damage and the chromatin factors mediating repair of these lesions have been extensively studied. However, DSBs are rare, and more common threats to the genome include single-strand DNA gaps, nicks, base lesions, stalled replication forks, and non-canonical DNA topology that can interfere with replication and repair. The chromatin modifications that are occurring during these other types of DNA repair pathways remain less well-characterized than DSB repair because of the technical difficulty associated with studying a site-specific, nonDSB lesion compared to robust DSB-inducing systems. However, studies have started to elucidate the contribution of histone modifications to non-DSB lesions (Figure 1). This review will focus on the chromatin modifications known to date to contribute to repair of single-strand DNA gaps, stalled forks, DNA structures, base lesions and mismatches, and will compare and contrast these marks to those known to occur during DSB repair.

\section{CHROMATIN MODIFICATIONS AND REMODELING DURING DSB REPAIR}

At the occurrence of a DSB, the MRN (MRX in yeast) complex binds the broken DNA ends, which recruits the PIKK kinases, ATR/ATM (Mec1/Tel1 in yeast); alternatively, the broken ends are bound by the $\mathrm{Ku} 70 / \mathrm{Ku} 80$ heterodimer, which recruits DNA-PK (Gottlieb and Jackson, 1993; Mahaney et al., 2009). These kinases phosphorylate H2AX, thus forming $\gamma \mathrm{H} 2 \mathrm{AX}$ and initiating the chromatin response to DNA 


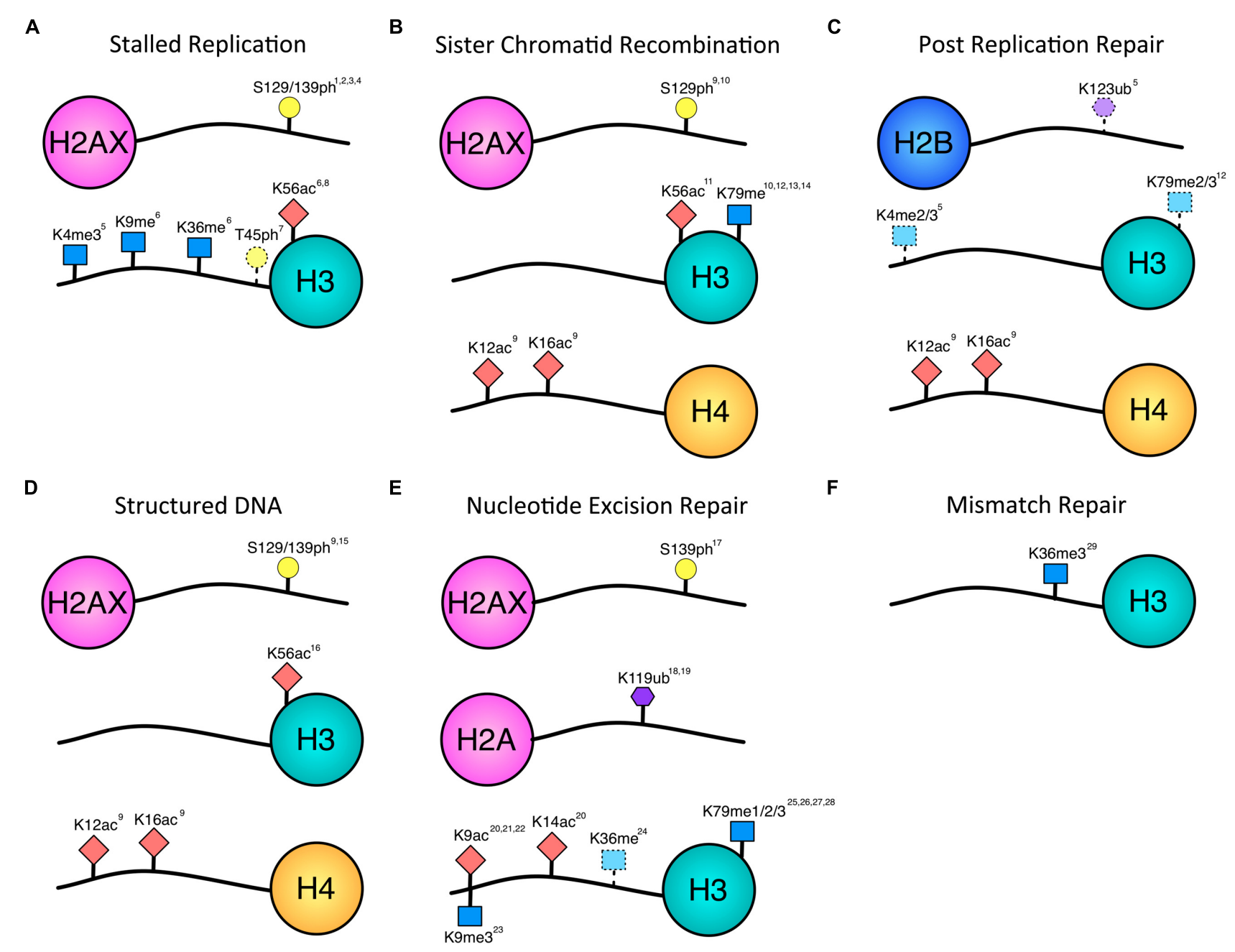

FIGURE 1 | Histone modifications associated with repair of single-stranded lesions. Histone phosphorylation (yellow circle), acetylation (red diamond), methylation (blue square), and ubiquitination (purple hexagon) have all been implicated in repair outside of DSBs. Numbering of modified residues is according to the organism in which the modification was identified in the referenced work. Dotted lines indicate uncertainty of pathway association. (A) Histone modifications documented to occur in response to stalled replication forks. There is overlap with modifications associated with DSBs, and future data may provide further distinction between stalled and collapsed forks. (B) Modifications associated with sister chromatid recombination in response to gaps or DSBs. While the $\mathrm{H} 3$ modifications have been implicated in DSB SCR, the $\mathrm{H} 2 \mathrm{~A}$ and $\mathrm{H} 4$ modifications have been associated with the fidelity of gap-induced SCR. (C) H4-K12ac, and H4-K16ac have been implicated in error-free PRR. H2B-K123ub, H3-K4me, H3-K79me are dependent on Rad6, which is required for PRR. However, they have not yet been shown to be necessary for PRR and may contribute to other homology-mediate repair events. (D) Histone modifications associated with structured DNA. These modifications also impact the fidelity with which the DNA is repaired. (E) Histone modifications occurring during nucleotide excision repair. A decrease in $\mathrm{H} 3-\mathrm{K} 9 \mathrm{me}$ is indicated by the downward facing blue square. H3-K36 methylation may be associated with transcription and/or TCR. (F) The only histone modification shown to be necessary so far for mismatch repair is H3K36 methylation. ${ }^{1}$ Cobb et al. (2005), ${ }^{2}$ Szilard et al. (2010), 3 Ward and Chen (2001), ${ }^{4}$ Sirbu etal. (2011), ${ }^{5}$ Faucher and Wellinger (2010), 6 Kim etal. (2008), ${ }^{7}$ Baker etal. (2010), ${ }^{8}$ Wurtele etal. (2012), 9 House et al. (2014), ${ }^{10}$ Conde etal. (2009), ${ }^{11}$ Munoz-Galvan etal. (2013), ${ }^{12}$ Game et al. (2006), ${ }^{13}$ Toh et al. (2006), ${ }^{14}$ Grenon etal. (2007), ${ }^{15}$ Entezam and Usdin (2008), 16Yang and Freudenreich (2010), ${ }^{17}$ O'Driscoll et al. (2003), 18 Kapetanaki et al. (2006), ${ }^{19}$ Bergink et al. (2006), 20Yu et al. (2005), 21 Guo et al. (2011), ${ }^{22}$ Rubbi and Milner (2003), ${ }^{23}$ Palomera-Sanchez et al. (2010), ${ }^{24}$ Malik etal. (2010), ${ }^{25}$ Evans etal. (2008), ${ }^{26}$ Bostelman et al. (2007),

${ }^{27}$ Chaudhuri etal. (2009), ${ }^{28}$ Tatum and Li (2011), ${ }^{29}$ Li et al. (2013). damage (Rogakou etal., 1998; Downs et al., 2004; Ataian and Krebs, 2006; Bao, 2011). The histone modifications documented to occur during DSB repair will be briefly summarized here in order to provide context for comparison to other repair pathways. For recent, more detailed reviews, see Chubb and Rea (2010), Zhu and Wani (2010), Bao (2011), Greenberg (2011), Miller and Jackson (2012), Seeber et al. (2013), Price and D’Andrea (2013), and Tsabar and Haber (2013).

\section{$\gamma \mathrm{H} 2 \mathrm{AX}$ AT DSBs}

$\gamma \mathrm{H} 2 \mathrm{AX}$ (H2AX-S139ph in mammals; H2A-S129ph in yeast) is the most well-documented histone modification in response to a DNA DSB and occurs within minutes of break induction (Rogakou et al., 1998; Shroff et al., 2004; Stiff et al., 2004, 2006). The $\gamma \mathrm{H} 2 \mathrm{AX}$ domains are established by a positive feedback loop whereby $\gamma \mathrm{H} 2 \mathrm{AX}$ recruits the mammalian repair mediator MDC1, which in turn recruits additional MRN that will stimulate further 
phosphorylation of H2AX by ATM (Uziel et al., 2003; Lukas et al., 2004; Lee and Paull, 2005; Stucki et al., 2005; Lou et al., 2006). This MDC1-ATM pathway to amplify the $\gamma \mathrm{H} 2 \mathrm{AX}$ signal increases the density of $\gamma \mathrm{H} 2 \mathrm{AX}$ proximal to the break site; however, subsequent spreading of $\gamma \mathrm{H} 2 \mathrm{AX}$ to create large domains is dependent on the action of ATM, but not MDC1 (Savic et al., 2009). Earlier data in yeast indicated that the $\gamma \mathrm{H} 2 \mathrm{AX}$ modification is necessary for the recruitment of chromatin modifying enzymes, including INO80 and SWR1 remodelers (Downs et al., 2004; Morrison et al., 2004; van Attikum et al., 2004), which can alter the chromatin structure to allow access by other repair proteins, such as 53BP1, Rad51, and BRCA1 (Paull et al., 2000; Celeste et al., 2003a,b; Murr et al., 2006; Shi and Oberdoerffer, 2012; Scully and Xie, 2013). However, recent work in yeast demonstrated that the $\gamma \mathrm{H} 2 \mathrm{AX}$ modification is dispensable for recruitment of the chromatin modifying enzymes INO80, SWR-C, NuA4, SWI/SNF, or RSC to DSBs during homologous recombination in G2 cells (Bennett et al., 2013), suggesting that the repair proteins are not necessarily directly recruited by an interaction with $\gamma \mathrm{H} 2 \mathrm{AX}$. Instead, recruitment of chromatin modifiers and remodelers in G2 is tightly coupled to homologous recombination, and the Rad51 filament itself may play a role (Bennett et al., 2013). In any case, $\gamma \mathrm{H} 2 \mathrm{AX}$ modification is an early step in a cascade of chromatin modifications, including nucleosome remodeling and other post-translational histone modifications, which allows for subsequent recruitment and retention of repair factors. Although many histone modifications that contribute to DSB repair have been identified, the order of events is only partially understood (Bao, 2011).

In addition to $\gamma \mathrm{H} 2 \mathrm{AX}$, other histone modifications are required for efficient repair of DSBs, including acetylation, methylation, and ubiquitination of lysine residues. The modification of amino acid residues can be influenced by existing histone modifications. For example, H4-S1 phosphorylation after DNA damage is required for $\mathrm{H} 4 \mathrm{~N}$-tail lysine deacetylation (Cheung et al., 2005; Utley et al., 2005), and $\mathrm{H} 2 \mathrm{~B}$ ubiquitination is required for $\mathrm{H} 3$ methylation (Game and Chernikova, 2009; discussed below). This presents the interesting possibility that ordered progression of modifications could allow for regulation of repair events or be important in promoting proper repair.

\section{HISTONE METHYLATION}

Defective methylation of H3-K79 and H3-K36 results in ionizing radiation (IR) sensitivity in yeast cells (Game et al., 2005, 2006; Grenon et al., 2007; Game and Chernikova, 2009). In mammalian cells, H3-K79 methylation, along with H4-K20 dimethylation, are recognized by 53BP1 in relaxed chromatin at the DSB (Hartlerode et al., 2012; Wakeman et al., 2012; Hsiao and Mizzen, 2013). $\mathrm{H} 3-\mathrm{K} 9 \mathrm{me}$, on the other hand, stimulates TIP60 histone acetyltransferase (HAT) activity at the break site, resulting in acetylation of both histones and ATM, the latter activating the kinase to further stimulate $\gamma \mathrm{H} 2 \mathrm{AX}$ formation (Ikura et al., 2000; Murr et al., 2006; Xu et al., 2010, 2012; Bao, 2011; Xu and Price, 2011).

\section{HISTONE UBIOUITINATION}

Histone ubiquitination has been implicated in several steps of DSB repair (Bao, 2011). H2AX-K119 ubiquitination is induced upon IR treatment (Xie et al., 2010) and is required for histone turnover at the site of damage (Ikura et al., 2007). H2A/H2A.X ubiquitination by RNF8 and RNF168 is also required for accumulation and retention of 53BP1 and BRCA1 at the break (Huen et al., 2007; Kolas et al., 2007; Mailand et al., 2007; Doil et al., 2009). H3 and H4 ubiquitination have also been shown to facilitate the recruitment of repair factors to a DSB, and in mammalian cells monoubiquitination of $\mathrm{H} 2 \mathrm{~B}-\mathrm{K} 120$ is required for recruitment of both HR and NHEJ repair factors and may contribute to chromatin decompaction to promote repair (Wang et al., 2006; Moyal etal., 2011). In yeast, ubiquitination of H2B-K123 is a prerequisite for $\mathrm{H} 3-\mathrm{K} 4$ and $\mathrm{H} 3-\mathrm{K} 79$ methylation and is necessary for Rad53 phosphorylation in response to DNA damage (Giannattasio et al., 2005).

\section{HISTONE ACETYLATION AND DEACETYLATION}

Histone acetylation flanking a DSB is required for repair and cellular survival after DNA damage in both yeast and mammalian cells (Bird et al., 2002; Downs et al., 2004; Tamburini and Tyler, 2005; Murr et al., 2006; Xu et al., 2010). In yeast, histone lysine residues are acetylated at DSB sites by Gnc5, an H3-specific HAT recruited by $\gamma \mathrm{H} 2 \mathrm{AX}$ (Lee et al., 2010); in mammalian cells, histones are acetylated by TIP60, the NuA4 complex HAT that is recruited to a DSB by a physical interaction with the MRN complex (Chailleux et al., 2010). An additional mammalian HAT, MOF, acetylates histone $\mathrm{H} 4-\mathrm{K} 16$ and this modification is required for the recruitment of repair factors to an irradiation-induced break site, including MDC1, 53BP1, and Brcal (Li et al., 2010; Krishnan et al., 2011).

As histone modifications are required to alter the chromatin environment to facilitate repair, additional modifications are required to reset the chromatin state once repair is complete. Histone deacetylases (HDACs) are recruited to remove histone acetyl marks and restore the chromatin structure in yeast (Tamburini and Tyler, 2005). However, HDACs may also play a more direct role in the repair process, as in mammalian cells HDACs are recruited to a DSB early in the repair process (Bao, 2011; $\mathrm{Xu}$ and Price, 2011). In mammalian cells, the HDAC SIRT1 is recruited to an I-SceI DSB (Oberdoerffer et al., 2008), and the HDAC complex NuRD, which includes HDAC1 and HDAC2, is recruited to a microirradiation-induced DSB to deacetylate H3K56 (Miller et al., 2010), a histone modification that promotes nucleosome assembly during replication and repair (Chen et al., 2008; Li et al., 2008).

\section{CHROMATIN REMODELERS}

Chromatin remodelers have also been shown to play an important role in DSB repair. Interestingly, the NuRD HDAC complex contains a chromatin remodeler subunit (MTA1 or 2), and the NuA4 HAT complex contains the chromatin remodeler p400 (Xu and Price, 2011; Price and D'Andrea, 2013), intimately linking the role of histone modifications and chromatin remodeling. p400 (SWR1 in yeast) has recently been shown to catalyze the exchange of the $\mathrm{H} 2 \mathrm{~A}$ variant $\mathrm{H} 2 \mathrm{~A} . \mathrm{Z}$ onto the chromatin at DSBs, which leads to a more open chromatin structure and promotes further histone modifications at the site of damage (Xu et al., 2012). Once at the site of damage, SWR1 stimulates the exchange of H2A.Z onto the chromatin and this exchange is promoted by both $\mathrm{H} 2 \mathrm{~A}$ and $\mathrm{H} 4$ 
acetylation (Altaf et al., 2010). In yeast, the direction of exchange (H2AX for H2A.Z or H2A.Z for H2AX) is influenced by H3-K56 acetylation state: SWR-C preferentially removes H2A.Z from the nucleosome when $\mathrm{H} 3$ is acetylated at $\mathrm{K} 56$ (H3-K56Q acetyl-mimic mutant), and thus the specific catalytic activity of the SWR-C remodeler is determined by histone modification state to promote turnover of histone variants (Watanabe et al., 2013). SWR1 also facilitates Ku80 binding at the break, thereby promoting NHEJ (van Attikum et al., 2007; Bao, 2011).

Chromatin remodelers appear to play a key role during repair, but the exact function of many remodelers remains unknown. What DNA topological substrate is specifying remodeler recruitment or action and how histone modifications contribute to this process or remodeler function remain to be elucidated. Chromatin remodelers may be required during repair to open the damaged DNA to other repair proteins; alternatively, remodelers could be important to downregulate transcription in the vicinity of the break to limit collisions between the repair machinery and transcription machinery, allowing repair to progress properly (Kruhlak et al., 2007; Shanbhag et al., 2010). More generally, a transient repressive chromatin state may be important for stabilization of the chromatin fiber for efficient repair, as was a proposed role for H3-K9me3 at a DSB (Ayrapetov et al., 2014). In addition to physically altering the chromatin to facilitate proper access to the DNA template, remodelers could be more directly involved in the subsequent cascade of damage signaling by directly interacting with other repair factors, perhaps acting as recruitment platforms or mediators.

\section{CHROMATIN MODIFICATIONS ASSOCIATED WITH STALLED REPLICATION FORKS}

Stalled replication forks can be protective to genomic integrity, given that the stall can avoid replication through damaged DNA and signal the location of DNA damage to be repaired. However, if the damage is not repaired or bypassed, or if a single-strand break is in the template, the stalled fork can collapse, leading to a DSB. For example, low doses of aphidicolin can induce replication stress that will stall forks and leave single-strand gaps, eventually resulting in DSBs (Freudenreich, 2007). Interestingly, aphidicolin treatment during $\mathrm{S}$ phase induces $\gamma \mathrm{H} 2 \mathrm{AX}$-dependent 53BP1 foci in the next $G_{1}$ phase, indicating that a fork stall not resolved by mitosis can lead to a DSB in the next cell cycle (Harrigan et al., 2011; Lukas et al., 2011).

To prevent DSB formation, damage tolerance pathways can be invoked, leaving the damage to be resolved through postreplication repair (PRR). Error-prone PRR occurs by recruitment of a translesion synthesis (TLS) polymerase that can bypass the lesion. Alternatively, a template switch involving sister chromatid annealing can allow the polymerase to copy the homologous sequence information from the sister chromatid and continue replication, or sister chromatid recombination (SCR) can be used to repair a gap left after fork passage. Thus, since fork stalling can lead to TLS, template switching, SCR, or a DSB, it can be experimentally difficult to distinguish the chromatin modifications that are specific to the initial fork stall or to each subsequent repair pathway. Stalling replication forks with low levels of hydroxyurea (HU) or inducing site-specific stalls with
DNA-bound proteins or known fork-stalling DNA sequences, such as CGG repeats, can be effective strategies to uncover chromatin modifications associated with stalled replication forks. In addition, co-localization experiments using ChIP or isolation of proteins on nascent DNA (iPOND, Sirbu etal., 2012; see below) have been productive in linking replication forkassociated factors with chromatin-associated factors. This section will focus on the histone modifications and chromatin remodelers known to-date to be associated with stalled replication forks.

Stalled replication forks are marked in the chromatin as DNA damage, as $\gamma \mathrm{H} 2 \mathrm{AX}$ domains form at stalled replication forks (Figure 1A). In yeast, phosphorylated $\mathrm{H} 2 \mathrm{~A}(\gamma \mathrm{H} 2 \mathrm{~A})$ was found to co-localize with $\mathrm{HU}$ stalled forks and Pol $\varepsilon$ by ChIP, and this event was dependent on the Mecl but not the Tell kinase, distinguishing the modification from $\gamma \mathrm{H} 2 \mathrm{~A}$ at a DSB which can be phosphorylated by both Mec1 and Tel1 (Cobb et al., 2005). Indeed, genome-wide mapping of $\gamma \mathrm{H} 2 \mathrm{~A}$-rich loci using ChIP technology revealed that $\gamma \mathrm{H} 2 \mathrm{~A}$ is enriched at sites of natural replication fork stalling, including the rDNA locus, tRNA genes, LTRs, telomeres, and DNA replication origins (Szilard et al., 2010). Interestingly, the average size of the $\gamma \mathrm{H} 2 \mathrm{~A}$ domain at these natural pause sites was $1255 \mathrm{bp}$, in contrast to the $50 \mathrm{~kb}$ domain detected at an HO endonuclease-induced DSB in yeast cells. Functionally, H2A modification is required to promote replication fork progression, as measured by total DNA content after release from $\mathrm{G}_{1}$ in mecl-ts mutants, and prevent DSB formation, as measured by pulsed-field gel electrophoresis (Cha and Kleckner, 2002).

In mammalian cells, $\gamma \mathrm{H} 2 \mathrm{AX}$ is induced when DNA replication is inhibited by HU, forming foci that co-localize with PCNA in S phase cells, and this response is also dependent on ATR but not ATM (Ward and Chen, 2001). Using iPOND technology to monitor protein dynamics at sites of newly synthesized DNA in live mammalian cells, $\gamma \mathrm{H} 2 \mathrm{AX}$ was detected at a stalled replication fork within $10 \mathrm{~min}$ after $\mathrm{HU}$ addition, becoming maximal at $30 \mathrm{~min}$ (Sirbu et al., 2011). These early time points were not accompanied by markers of DSBs such as Mre11, DNA-PK, or $\mathrm{Ku} 70 / \mathrm{Ku} 80$ which appeared at later time points $2-4 \mathrm{~h}$ after $\mathrm{HU}$ addition, indicating that the early $\gamma \mathrm{H} 2 \mathrm{AX}$ is not marking collapsed forks or DSBs. The $\gamma \mathrm{H} 2 \mathrm{AX}$ domain spread from the site of fork stalling over time, reaching tens of thousands of base pairs by $1 \mathrm{~h}$. Again, initial $\gamma \mathrm{H} 2 \mathrm{AX}$ formation at an HU-stalled replication fork was ATR-dependent; but maintenance of the $\gamma \mathrm{H} 2 \mathrm{AX}$ domain at later time points was ATM-dependent, likely occurring once the persistently stalled fork had collapsed into a DSB (Sirbu et al., 2011).

While both DSBs and stalled forks are marked by an initial $\gamma \mathrm{H} 2 \mathrm{AX}$ histone modification, subsequent chromatin modifications dependent on either ATM or ATR could produce chromatin environments specific to the lesion type, directing repair to the appropriate pathway or influencing the repair process itself. The histone modifications important for turning off the DNA damage response at a stalled fork may also be different than at a DSB. To turn off the DSB-induced checkpoint, mammalian serine/threonine phosphatase complexes PP2A and PP4 and the yeast PP4C ortholog Pph3 dephosphorylate $\gamma \mathrm{H} 2 \mathrm{AX}$, leading to inactivation of Rad53 (Chowdhury et al., 2005; Keogh et al., 2006; Nakada 
et al., 2008). However, another phosphatase, PP1 (Glc7), has been shown to dephosphorylate $\gamma \mathrm{H} 2 \mathrm{AX}$ and contribute to Rad53 inactivation and replication fork restart after HU treatment (Bazzi etal., 2010). Of note, PP4 in mammalian cells appears to be especially important for resolution of DNA damage that occurs during replication, specifically dephosphorylating ATR (but not ATM)-modified $\gamma \mathrm{H} 2 \mathrm{AX}$ (Chowdhury et al., 2008).

Although much research has focused on $\gamma \mathrm{H} 2 \mathrm{AX}$ at stalled replication forks, other histone modifications are likely occurring to influence replication fork recovery or repair (Figure 1A). One such modification is phosphorylation of H3-T45 in yeast, a modification observed in response to prolonged replication stress in HU treated cells that is independent of the Mec1 and Tell kinases and is instead regulated by the Cdc7-Dbf4 kinase complex (Baker etal., 2010). The authors conclude that this modification is specific to replication stress, as treatment with DNA alkylating agent MMS did not increase H3-T45 phosphorylation. Further, the H3-T45A mutant was not sensitive to MMS, but was sensitive to HU and CPT, a topoisomerase I inhibitor, as measured by cell survival in a spot assay (Baker et al., 2010). However, prolonged exposure to $\mathrm{HU}$ and CPT will lead to DSB formation and therefore this modification could mark DSBs, although in a Mec1/Tel1-independent manner.

In addition to histone phosphorylation, histone acetylation, methylation, and ubiquitination likely play a role in signaling replication stress (Figure 1A). In human T-cell lymphoma cells, HDAC3 is localized to replication forks by iPOND, linking changing acetylation state with newly synthesized DNA (Wells et al., 2013). Further, HDAC3 inhibition resulted in decreased replication fork velocity and increased apoptosis that was associated with increased DNA damage and an S phase defect (Wells et al., 2013). In budding yeast, H3-K56 acetylation is required to complete replication in the presence of lesions caused by MMS (Wurtele etal., 2012). In fission yeast, the absence of Clr4 and Set2, the methyltranferases for $\mathrm{H} 3-\mathrm{K} 9$ and $\mathrm{H} 3-\mathrm{K} 36$, respectively, leads to a decrease in HU-induced phosphorylation of Cdc2 and Mik1, downstream actors in the Rad3 (human ATM) checkpoint pathway. Therefore, the authors conclude that the HU replication stress checkpoint requires $\mathrm{H} 3$ methylation by $\mathrm{Clr} 4$ and Set2 (Kim et al., 2008). H3-K4 trimethylation may also contribute to repair of $S$ phase damage in S. cerevisiae, as the absence of Set1, the HMT responsible for $\mathrm{H} 3-\mathrm{K} 4$ trimethylation, leads to an $\mathrm{S}$ phase progression defect, in addition to the role of Set1 in NHEJ (Faucher and Wellinger, 2010). Histone H3-K4 and K79 methylation, regulated by H2B-123 ubiquitination, may also play a role in PRR, which would be initiated after a replication fork stalling event (discussed in next section).

Chromatin remodeling is also important in resolving the damage at a stalled replication fork (Table 1). INO80 is implicated in recovery from stalled replication in both budding yeast and mammalian cells. In mammalian cells, ino 80 mutants are HU sensitive, display defective $S$ phase progression, and are defective in recovery from replication stress (Hur et al., 2010; Min et al., 2013; Vassileva et al., 2014). In yeast, Ino80 is enriched at stalled replication forks, as detected by ChIP (Papamichos-Chronakis and Peterson, 2008; Shimada et al., 2008). In addition, recovery from replication fork stalling after HU treatment is impaired in an ino80 mutant, resulting in DSBs (Shimada et al., 2008), and Ino80 promotes replication restart after MMS treatment (Falbo et al., 2009). In the absence of both an intact INO80 complex and the chromatin remodeler Isw2, recovery from the $S$ phase checkpoint response is defective (Au et al., 2011). The chromatin remodeler RSC2 may also play a role in recovery from stalled replication or be involved in PRR. In S. cerevisiae, RSC2 is found near replication forks by ChIP, and PCNA ubiqutination is significantly decreased in a $r s c 2 \Delta$ mutant after MMS, UV, and HU treatments (Niimi et al., 2012). Similarly, depletion of the human homolog BAF180 of the PBAF complex led to a decrease in fork progression by IdU incorporation (DNA fiber) analysis and decreased chromatin bound unmodified and ubiquitin-modified PCNA and Rad18 (Niimi et al., 2012). Other remodelers are found at replicating forks irrespective of a stall, but may also play a role at stalled forks (Vincent et al., 2008; Au et al., 2011; Bhaskara et al., 2013).

It is likely that additional histone modifications are associated with recovery from stalled replication forks, but they remain to be identified. Histone modifications could influence several steps of recovery from stalled replication, including marking the location of a stalled fork, recruitment of replication restart factors or replication bypass factors (including translesion synthesis polymerases), establishing sister chromatid cohesion for homology-mediated PRR, and finally the recruitment of chromatin modifying enzymes to reset the chromatin structure.

\section{CHROMATIN MODIFICATIONS IN RESPONSE TO SINGLE-STRAND GAPS REPAIRED BY SISTER CHROMATID RECOMBINATION OR TEMPLATE SWITCHING}

More common than DSBs are single strand DNA lesions that can occur during replication and repair. Single strand gaps that occur during replication will activate the DNA damage checkpoint (Branzei and Foiani, 2008). These gaps activate the kinase ATR, not ATM, and the intensity of the checkpoint response increases with increasing gap length, as monitored by Chk1 phosphorylation (MacDougall et al., 2007). To prevent gaps from becoming DSBs, Rad6-Rad18 dependent damage tolerant replication can be invoked to allow replication to continue, followed by subsequent repair of the template-strand lesion in a process that has been termed PRR. Single-stranded gaps that occur during replication must be resolved before the following $S$ phase to prevent the formation of DSBs. Base damage, for example by alkylating agents such as MMS, result in unreplicated gaps left after fork passage (Hashimoto et al., 2010). It is probable that repair of nicks and gaps will have overlapping histone modifications with DSB repair, particularly if the lesion induces a checkpoint response. However, it is also likely that different combinations of histone modifications will distinguish nick and gap repair pathways from repair of a DSB.

\section{POST-REPLICATION REPAIR}

Post-replication repair can be divided into two Rad6-dependent, damage tolerant pathways: error-prone TLS and error-free PRR. 
Table 1 | Chromatin remodelers associated with repair pathways outside of DSB repair.

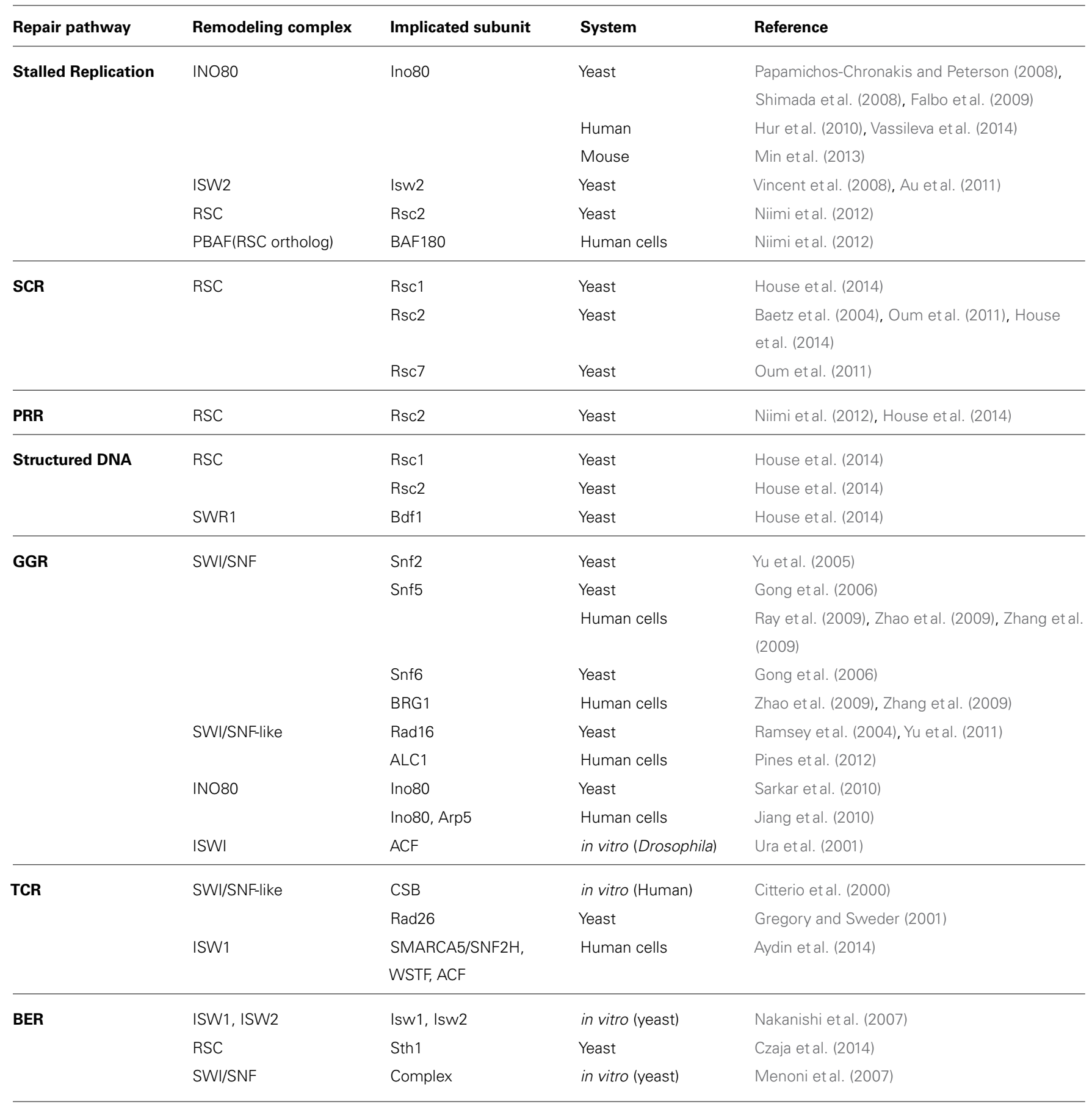

TLS is initiated by Rad6-Rad18 monoubiquitination of PCNA and allows replication past a lesion by employing low-fidelity translesion polymerases with large active sites that can accommodate bulky lesions. Rad6 is the E2 ubiquitin-conjugating enzyme that cooperates with the E3 ubiquitin ligase Rad18 to modify PCNA to initiate PRR. However, with the E3 ubiquitin ligase Bre1, Rad6 also plays a role in regulating histone $\mathrm{H} 2 \mathrm{~B}-\mathrm{K} 123$ ubiquitination (Briggs et al., 2002; Dover et al., 2002; Ng et al., 2002; Game and Chernikova, 2009). H2B-K123 ubiquitination promotes H3-K4 and H3-K79 di- and tri-methylation by Set1 and Dot1, respectively (Briggs et al., 2001; Miller et al., 2001; Shahbazian et al., 2005; Fuchs et al., 2009; Nakanishi et al., 2009; Takahashi et al., 2009). Given the regulation by Rad6, H2B-K123 ubiquitination and $\mathrm{H} 3-\mathrm{K} 4$ and $\mathrm{H} 3-\mathrm{K} 79$ methylation may play a role in PRR (Figure 1C). To date, no histone modifications are identified to contribute specifically to the TLS branch of PRR, but the HAT Gcn5 is required for transcription of the TLS polymerase $\eta$ (Kikuchi et al., 2012). 
Error-free PRR requires polyubiquitination of PCNA by Ubc13-Mms2 and Rad5, which initiates a template switch to bypass the template strand lesion and copy from the newly synthesized sister chromatid. The recombination event during error-free PRR further requires the action of Rad52 epistasis group members (Boiteux and Jinks-Robertson, 2013). Thus, a post-replication template switch is mechanistically very similar to gap-induced sister chromatid recombination, and may be marked by similar or identical histone modifications. Until recently, no particular histone modifications had been attributed to error-free PRR or gap-induced SCR. However, our group has recently found that acetylation of histone $\mathrm{H} 4$ by the HAT Esal of the NuA4 complex is needed for stability of CAG repeats in a Rad5-dependent manner (Figure 1C). Furthermore, the HAT activity of NuA4 is required for gap-induced SCR. The most important modifications are acetylation of H4-K12 and H4-K16, known targets of Esa1 (Figure 1B). Additionally, H4-K16 acetylation at the CAG repeat peaks during $S$ phase, but then disappears, presumably once repair is complete. A dynamic nature to the histone acetylation appears to be important in maintaining genomic stability, as both HAT and HDAC mutants displayed an increased frequency of CAG repeat expansions. If histone acetylation was primarily acting to disrupt higher order chromatin compaction to open the chromatin structure (Murr et al., 2006; Shogren-Knaak et al., 2006), the HDAC mutant would have rescued genomic stability by allowing constant decompaction of the chromatin. As this was not the case, the requirement for dynamic histone $\mathrm{H} 4$ acetylation argues for a model in which the modification is directly affecting recruitment or turnover of repair factors to facilitate PRR of gaps via SCR.

\section{SISTER CHROMATID RECOMBINATION}

Sister chromatid recombination is a homology-mediated event that contributes to both DSB repair when a sister chromatid is available as well as post-replication single strand gap repair. Chromatin modifications associated with SCR have been identified mostly within the context of a DSB, but since the physical recombination event in DSB and PRR will be similar, it is reasonable to expect that some histone modifications will affect both repair pathways. One potential example of this is H3-K56 acetylation. Not only does H3-K56 acetylation respond to replication fork damage (Wurtele et al., 2012), but it also works with Rad52 to promote SCR during repair of a DSB (Munoz-Galvan et al., 2013; Figures 1A,B). H3-K56 acetylation was also shown to be important in preventing CAG repeat fragility and contractions during both replication and Rad52-dependent repair events (Yang and Freudenreich, 2010; Figure 1D). In human cells, TIP60-dependent $\mathrm{H} 4$ acetylation has been shown to promote BRCA1-dependent HR (Tang et al., 2013), and depletion of the H4K16-specific HAT MOF leads to a decrease in DSB-induced HR and sister-chromatid exchanges (Li et al., 2010; Sharma et al., 2010), suggesting that H4 acetylation is important in facilitating homology-dependent recombination events between sister chromatids.

Sister chromatid cohesion is necessary for proper alignment of homologous sequences during SCR. Contributing to this process is the RSC complex, which is required to recruit cohesin to chromosomes (Baetz et al., 2004), and also to recruit the cohesin subunits Smc1 and Scc1 to a DSB (Oum et al., 2011). These results link chromatin remodeling to cohesin loading during recombination. Lending support to a role for RSC in SCR is that $r s c 2$ or rsc7 deletions confer sensitivity to MMS during $G_{2}$ but not $G_{1}$, indicating RSC is most important after synthesis when the sister chromatid would be available as a template for repair. Indeed, the $r s c 7$ mutant has a decrease in spontaneous sister chromatid exchange (Oum et al., 2011), and we found that both rsc1 and $r s c 2$ mutants were defective in spontaneous SCR (House et al., 2014; Table 1). Interestingly however, only Rsc2 is able to suppress an MMS-induced increase in SCR, implicating the Rsc2 sub-complex specifically in gap-induced SCR (Table 1; House etal., 2014). Additionally, the Rsc2 sub-complex is detected by ChIP at an unstable CAG repeat coincident with $\mathrm{H} 4 \mathrm{~K} 16 \mathrm{ac}$, suggesting a possible recruitment mechanism for this remodeler during gap-induced repair from the sister chromatid (House et al., 2014). Both efficient $\gamma \mathrm{H} 2 \mathrm{AX}$ modification at a break site (Kent et al., 2007) and MRX recruitment to a DSB (Shim et al., 2007) are dependent on RSC. Therefore, this chromatin remodeling complex may be a common component of HR repair induced by either a DSB or gap that links the initial damage event to the subsequent chromatin response.

In addition to histone acetylation, both histone methylation and phosphorylation are required for proper SCR (Figure 1B). In yeast, the histone methyltransferase Dot1 has specificity for the $\mathrm{H} 3-\mathrm{K} 79$ residue and is required for DSB break repair (Game et al., 2006; Game and Chernikova, 2009). In the absence of Dot1, cells lose IR-induced Rad9 foci in $\mathrm{G}_{2}$, suggesting a role for this modification in recruitment of Rad9 specifically when a sister chromatid is present (Toh et al., 2006; Grenon et al., 2007). Further, using a physical assay to probe for recombination intermediates and monitor unequal exchange of sister chromatids upon replication of a DSB lesion, Conde et al. (2009) found that the unphosphorylatable H2A-S129A mutant and the dot1 $\Delta$ mutant are defective in SCR and are contributing to repair by promoting sister chromatid cohesion (Conde et al., 2009).

As the chromatin modifications and remodeling required to promote single-strand gap repair, PRR, and SCR continue to be defined, it is probable that more specific combinations of histone modifications will be revealed to be distinct from those required for DSB repair. Histone modifications could contribute to altering the chromatin environment to promote recombination, either directly by changing charge interactions between nucleosomes and the DNA, or indirectly through repair factor and chromatin remodeler recruitment. Specific histone modifications and remodelers may also contribute to the overall fidelity of repair, as illustrated by those that are needed to promote SCR as well as prevent CAG repeat instability (Figures 1B,D).

\section{THE CHROMATIN RESPONSE TO STRUCTURE-FORMING DNA}

Non-canonical DNA topology can lead to DNA lesions and must be resolved to prevent the loss of genomic material. Inverted repeats, some direct repeats, and homopyrimidine-homopurine runs can form stable secondary structures that impede DNA processing events, such as replication and repair, causing DNA damage and genome instability (Freudenreich, 2007; Voineagu et al., 2009a; Kim and Mirkin, 2013). Since DNA structures can 
cause all of the types of damage covered above, including DSBs, stalled forks, and single-strand DNA gaps or nicks, the modifications associated with structure-forming DNA will overlap with those found at these lesions. Indeed, structure-forming CGG/CCG and CAG/CTG triplet repeats induce replication fork stalling and chromosome fragility when they reach a length of 45 70 repeats (Samadashwily et al., 1997; Freudenreich et al., 1998; Balakumaran etal., 2000; Jankowski et al., 2000; Callahan et al., 2003; Kerrest et al., 2009; Voineagu et al., 2009b; Sundararajan etal., 2010), and even short triplet repeats can interfere with nick repair (Pearson et al., 2002). DNA structures, fork stalling, and unreplicated regions of DNA have also been associated with common fragile sites (Zhang and Freudenreich, 2007; Ozeri-Galai et al., 2012). Such hard-to-replicate regions will present a particular challenge to genomic integrity and histone modifications and chromatin-associated factors will be important in maintaining stability of these regions. Additionally, the properties of the repetitive DNA can affect the chromatin structure in the region by forming very stable nucleosomes or excluding nucleosomes (see below). Furthermore, the outcome of a defective repair process can be different in a repetitive DNA sequence compared to nonrepeat DNA: the built-in homology surrounding a lesion within a repeat could facilitate repair, but also lead to changes in the repeat number.

CAG repeats form stable DNA hairpins (Mirkin, 2007) and are strong nucleosome positioning elements (Wang et al., 1994; Wang and Griffith, 1995; Volle and Delaney, 2012). Long CAG repeats can activate the checkpoint response (Lahiri et al., 2004; Voineagu et al., 2009a,b; Sundararajan and Freudenreich, 2011), and expansions of the CAG repeat can occur during DNA repair if the process is inefficient (McMurray, 2010). We have found that lesions at an expanded $(\mathrm{CAG})_{155}$ repeat are marked by histone modifications. Both $\gamma \mathrm{H} 2 \mathrm{AX}$ and $\mathrm{H} 4 \mathrm{~N}$-terminal tail acetylation at residue K16 are enriched at an expanded CAG repeat during $S$ phase and are required to maintain stability of a $(\mathrm{CAG})_{85}$ repeat during SCR (House et al., 2014), suggesting that these histone modifications are required for high-fidelity repair of structured DNA, potentially through direct recruitment of chromatin remodelers (such as Rsc2) or other repair factors. In human cells, knockdown of class II HDAC9 leads to an increase in CAG repeat expansion frequency (Gannon et al., 2012). However, the opposite is true for HDAC3 and HDAC5, which promote CAG repeat expansions. Though the relevant target for these HDACs is unknown, it was shown that they act within the mismatch repair pathway to protect repeat stability (Gannon et al., 2012).

Whereas CAG repeats preferentially assemble nucleosomes, CGG repeats exclude nucleosomes (Wang, 2007; Kumari and Usdin, 2009). Despite the exclusion of nucleosomes, ATR is required to prevent CGG repeat expansions (Entezam and Usdin, 2008). This suggests that ATR may be phosphorylating H2AX near the CGG repeat to initiate chromatin modifications necessary for DNA repair. Given that CGG repeats are sites of replication fork stalling and chromosomal fragility, it is not surprising that histone modifications associated with DNA damage and repair are found near these sequence elements and are important for repeat stability (Usdin, 2008; Anand et al., 2012; Kumari et al., 2012).
Activation of the checkpoint response by expanded trinucleotide repeats indicates that the structures formed at these sequences are causing damage that initiates a repair event. It is possible that distinct histone modifications are contributing to repair of structured DNA, but the particular combination of modifications that are marking such lesions are only beginning to be identified.

\section{CHROMATIN MODIFICATIONS IMPORTANT FOR NUCLEOTIDE EXCISION REPAIR (NER)}

The nucleotide excision repair pathway is responsible for removing damage that distorts the DNA helix. This type of damage includes UV-induced 6-4photoproducts (6-4PPs) and cyclobutane pyrimidine dimers (CPDs), and repair requires lesion identification and excision. After lesion removal, nucleotides are re-synthesized and the DNA ends are ligated. Chromatin structure must be altered during the NER pathway, both by remodeling and modification of histones, to allow access to the damaged DNA by the proteins participating in the NER repair pathways. Important questions relevant to the NER pathway are whether chromatin relaxation occurs before or after detection of lesions, and the role of histone modifications in chromatin changes versus repair factor recruitment. In addition, chromatin structure must be re-established at the end of the repair process. There are two NER subpathways, and the pathway choice depends on if the DNA damage occurred on a DNA strand that is being actively transcribed: transcription-coupled repair (TCR) repairs damage that occurs on the transcribed strand, whereas global genomic repair (GGR) functions to repair damage that occurs on the nontranscribed strand of active genes or in inactive regions of the genome. Once the damage is recognized and repair is initiated, the two pathways use the same set of repair factors for the downstream events. For a more detailed review of NER in chromatin, see Reed (2011).

\section{GGR SUBPATHWAY: CHROMATIN MODIFICATIONS INVOLVED IN DAMAGE RECOGNITION AND REPAIR}

The GGR subpathway repairs damage that occurs on nontranscribed DNA strands, occurring mostly from exposure to UV radiation. The initial evidence that chromatin modifications occurred during the NER process came from the finding that histones were quickly acetylated after UV irradiation (Ramanathan and Smerdon, 1986). UV irradiation triggers genome-wide histone $\mathrm{H} 3$ and $\mathrm{H} 4$ hyperacetylation in yeast (Yu et al., 2005). Indeed, acetylation of histone $\mathrm{H} 3$, as well as other histone modifications described below, have been shown to facilitate the GGR pathway of NER (Figure 1E).

\section{HISTONE ACETYLATION}

After UV irradiation, histone $\mathrm{H} 3-\mathrm{K} 9$ and $\mathrm{K} 14$ were shown by ChIP to be hyperacetylated at the repressed MFA2 promoter in yeast (Yu et al., 2005; Figure 1E). This hyperacetylation was dependent on the yeast HAT Gcn5, deletion of which weakened the repair of damage at MFA2 as assayed by in vivo CPD removal (Yu et al., 2005). In yeast, both Gcn5 binding and the resulting histone H3K9 and K14 acetylation require Rad16 (Teng et al., 2008), a GGR factor with a potential function in chromatin remodeling because it is a SWI/SNF-related family member. Interestingly, the increased 
Gcn5 binding and $\mathrm{H} 3$ acetylation were dependent on both the ATPase and RING domains of Rad16, therefore both translocation and ubiquitin ligase activities are involved (Yu et al., 2011). The resulting $\mathrm{H} 3$ acetylation led to a more open chromatin state, measured by restriction enzyme accessibility, which was necessary for GGR (Yu et al., 2011). Recently, another factor in addition to Rad16 has been implicated in enhancing Gcn5 binding after UV damage: the histone H2A variant H2A.Z (Yu et al., 2013). Yeast strains that are deleted for $h t z 1$ are UV sensitive, have reduced histone acetylation, and are defective in removal of DNA damage caused by UV light (Yu et al., 2013). Altogether these studies support the conclusion that UV-induced histone acetylation promotes a more open chromatin structure that is necessary for efficient repair by the NER pathway.

A role for UV-induced histone H3-K9 acetylation during NER has also been observed in human cells. One pathway involves the transcription factor E2F1, which recruits the HAT Gcn5 to UV-damaged DNA (Guo et al., 2011). siRNA-knockdown of Gcn5 impaired recruitment of NER factors XPA and XPC to sites of damage, resulting in less efficient repair of CPDs and 6-4PPs (Guo et al., 2011). A second pathway of histone H3-K9 acetylation during NER has been linked to the function of p53, a tumor suppressor gene. Localization of the HAT p300 to sites of NER was dependent on p53, and H3-K9 acetylation after UV exposure was diminished in p53 mutants (Rubbi and Milner, 2003). Disruption of p300 caused complete NER inhibition, indicating that it is a key HAT in the GGR pathway. By monitoring micrococcal nuclease (MNase) sensitivity, p53 was found to mediate global chromatin relaxation following UV irradiation (Rubbi and Milner, 2003). Therefore, H3 acetylation by both Gcn5 and p300 together may be coordinating chromatin relaxation during NER in human cells.

\section{HISTONE METHYLATION}

Another histone modification recently connected to efficient GGR is histone methylation. Mono and di-methylation of histone H3K79 was increased in yeast strains with mutations that render the lysines on the $\mathrm{H} 4 \mathrm{~N}$-terminal tail unacetylatable, and the increase in methylation correlated with the severity of UV sensitivity of the H4 K to R mutations (Evans et al., 2008). This finding, therefore, suggests that histone $\mathrm{H} 4$ acetylation modulates histone H3-K79 methylation levels during UV damage repair (Figure 1E). Histone H3-K79 is methylated by the HMT Dot1, and $\operatorname{dot} 1 \Delta$ caused sensitivity to UV (Bostelman et al., 2007). Direct evidence for a role for Dot1 and H3-K79me in GGR was obtained by observation of defective repair of CPDs in the nontranscribed strand of RPB2 in mutants (Tatum and Li, 2011). In contrast, Dot1 and H3-K79 were not necessary for repair in the TCR subpathway, as measured by repair of the transcribed strand of RPB2 (Tatum and Li, 2011). Therefore, H3-K79 methylation during NER is a GGR-specific modification that may signal for recruitment of the GGR machinery to recognize damage and initiate repair. These findings contrast with a previous study that showed that a H3-K79R yeast mutant displayed almost normal NER at the expressed RPB2 gene, though NER at the transcriptionally silent cryptic mating-type locus $H M L$ was impaired (Chaudhuri et al., 2009). However, this study measured NER in both strands of the different loci and did not distinguish between the two strands, which may have therefore missed detection of the repair defect in the nontranscribed strand of $R P B 2$ observed by Tatum and Li (2011).

In contrast to the increased H3-K79 methylation during GGR observed in yeast, there is a global decrease in trimethylation of a different residue, H3-K9, following UV irradiation in fruit flies (Palomera-Sanchez et al., 2010; Figure 1E). UV irradiation increased levels of the histone H3-K9 demethylase, dKDM4B, and H3-K9 demethylation is necessary for repair of the UV lesions as repair of CPDs was impaired in flies with mutated dKDM4B (Palomera-Sanchez et al., 2010). These findings regarding the contrasting role of histone methylation at different $\mathrm{H} 3$ residues in the GGR pathway suggest that there may be a specific methylation pattern necessary to signal and recruit factors for repair of UV-induced DNA damage. Intriguingly, Drosophila with p53 mutations had higher levels of trimethylated H3-K9 after UV exposure (Palomera-Sanchez etal., 2010). It would be interesting to determine whether p53 mediates chromatin relaxation in flies, and whether this affects demethylase recruitment as it does HAT recruitment (see above).

\section{HISTONE UBIQUITINATION}

Histone ubiquitination has also been implicated in NER. In human fibroblasts, UV-induced DNA damage resulted in monoubiquitination of H2A-K119, but this modification was not observed in NER-deficient fibroblasts (Bergink et al., 2006; Figure 1E). As at DSBs, the NER-induced H2A ubiquitination was dependent on the E2-conjugating enzyme Ubc13 and the ubiquitin E3 ligase RNF8 (Marteijn et al., 2009). Additionally, the UV-damaged DNAbinding protein complex (UV-DDB) contains the subunit DDB2, a ubiquitin E3 ligase that targets histone H2A (Kapetanaki et al., 2006). Ubiquitination of $\mathrm{H} 2 \mathrm{~A}$ after exposure to UV was shown to be defective in cells from XP group E (XP-E) patients, who have a defect in UV-DDB (Kapetanaki et al., 2006). The ubiquitinated H2A may serve as a recognition signal for damage repair by NER factors that have ubiquitin-binding domains, such as RAD23B, which forms the damage recognition complex with XPC during the initial step of GGR (Kapetanaki et al., 2006). Overall, these findings highlight important associations between histone $\mathrm{H} 2 \mathrm{~A}$ ubiquitination and the NER pathway.

\section{HISTONE PHOSPHORYLATION}

A chromatin mark that is a hallmark of DSBs, $\gamma \mathrm{H} 2 \mathrm{AX}$ is also induced in a NER-dependent manner in UV-exposed nonreplicating human cells (O'Driscoll et al., 2003; Figure 1E). ATR is the primary kinase for NER-dependent $\gamma \mathrm{H} 2 \mathrm{AX}$ (Matsumoto et al., 2007). The precise function of $\gamma \mathrm{H} 2 \mathrm{AX}$ in NER remains to be clarified, but if it functions similarly to its role at DSBs, it may be involved in initiating repair events necessary for recruitment of NER factors.

\section{TCR SUBPATHWAY: POSSIBLE ROLE FOR CHROMATIN MODIFICATIONS}

The TCR pathway is activated when RNA polymerase II (RNAPII) stalls at lesions, recruiting factors for repair. Thus some histone modifications associated with active transcription may also have functions in the TCR pathway. 
Cockayne syndrome group B (CSB) protein and its homolog Rad26 in yeast are members of the SWI/SNF family of chromatin remodeling enzymes and are important for TCR (Guzder etal., 1996; Selby and Sancar, 1997a). A study by Fousteri etal. (2006) used a co-IP assay to identify proteins associated on the same chromatin fragment after UV treatment. Interactions between CSB, CSA (another TCR factor), and stalled RNAPII were identified, along with the HAT p300 and nucleosome binding protein HMGN1. CSB was necessary for the recruitment of the HAT p300 to stalled RNAPII, whereas the recruitment of HMGN1 was mediated via both CSB and CSA. The interaction between p300 and RNAPII was stimulated by UV and occurred prior to incision of lesions (Fousteri et al., 2006). Given the established role of p300 in NER (see above), it may be that histone acetylation is also needed to facilitate TCR.

In yeast, the association of the TCR factor Rad26 with chromatin is dependent on the presence of elongating RNAPII, and Rad26 is unable to identify lesions in the absence of transcription (Malik et al., 2010). ChIP experiments revealed that histone H3K36 methylation stimulated the interaction of Rad26 with DNA (Malik et al., 2010). Though not yet tested, the association with Rad 26 suggests that H3-K36 methylation may play a role in TCR (Figure 1E). However, since Rad26 also promotes transcriptional elongation, it may also be needed more generally to facilitate interaction of Rad26 with chromatin during transcription, rather than having any specific role during TCR.

A connection between ubiquitination and TCR was recently discovered. The deubiquitinating enzyme USP7 is brought to TCR complexes and stabilizes CSB. (Schwertman et al., 2012). TCR factors, including CSB, are known to be ubiquitinated and these could be targets of USP7 activity during TCR, potentially to protect TCR factors from UV-induced degradation. USP7 also deubiquitinates histone $\mathrm{H} 2 \mathrm{~B}$ and was recently implicated in base excision repair (BER; Khoronenkova et al., 2011). With several possible USP7 targets, the relevant ones for TCR remains to be established.

\section{CHROMATIN REMODELING IN THE NER PATHWAY}

As touched on above, chromatin accessibility plays a key role in NER, and histone acetylation and remodeling may work together to increase access to lesions for repair. Chromatin remodeling during NER has been summarized in a recent review, and compared to remodeling during repair of DSBs by the HR and NHEJ pathways (Lans et al., 2012). The role of chromatin remodelers in the NER subpathways will be highlighted here.

\section{REMODELING IN THE GGR SUBPATHWAY}

In yeast, the GGR factor Rad16 is a SWI/SNF-related family member with ATPase activity (Table 1). The ATPase activity of Rad16 is required for efficient repair (Ramsey et al., 2004; Yu et al., 2011), and it is therefore assumed that Rad16 is acting as a chromatin remodeler, although nucleosome displacement by Rad16 has not been directly observed. In addition, Rad 16 has been shown to promote Gcn5-dependent histone $\mathrm{H} 3$ acetylation during the repair of UV damage, and this leads to increased chromatin accessibility that is necessary for efficient damage repair (Yu et al., 2011).
A link between SWI/SNF chromatin remodeling and NER was discovered in yeast and is now well established. The NER damage recognition complex consisting of $\operatorname{Rad} 4$ and $\operatorname{Rad} 23$ (yeast homolog of human XPC-RAD23B) co-purified with Snf6 and Snf5, both SWI/SNF chromatin remodeling complex subunits, and the interactions increased with UV exposure (Gong et al., 2006; Table 1). Inactivation of SWI/SNF via snf6 $\Delta$ reduced restriction enzyme accessibility and affected the rate of CPD removal at the silent HML locus, implying that SWI/SNF is remodeling during NER (Gong et al., 2006). The double mutant rad16 snf6 $\Delta$ was more UV sensitive than the rad16 $\Delta$ single mutant, suggesting that Snf6 may have a role in TCR as well as GGR (Gong et al., 2006). Since Snf6 interacts with Rad4-Rad23 and Rad4 functions in both NER pathways (Verhage et al., 1994), it is possible for Snf6 to influence repair by both GGR and TCR. Additionally, following UV irradiation, chromatin was remodeled to increase DNA accessibility at MFA2, measured by restriction enzyme accessibility, which was partially dependent on the activity of the SWI/SNF ATPase Snf2 (Yu et al., 2005; Table 1). Overall, these findings support a function for SWI/SNF remodeling in the NER pathway.

Evidence for SWI/SNF chromatin remodeling during NER in mammals comes from BRG1 knockdown experiments that showed reduced repair of CPDs following damage with UV radiation, whereas restoring BRG1 in cells lacking the endogenous protein showed stimulation of NER (Zhang et al., 2009; Zhao et al., 2009; Table 1). In addition, SWI/SNF subunits BRG1 and SNF5 have been shown to physically interact with XPC (Ray et al., 2009; Zhao et al., 2009). In C. elegans, orthologs of mammalian SWI/SNF, including BRG1, BRM/SMARCA2, SNF5, PBRM1, and BAF155/SMARCC1 were implicated in survival after UV exposure (Lans et al., 2010).

A recent study revealed a function for poly (ADP-ribosyl)ation and chromatin remodeling during NER repair. Immunoprecipitation of DDB2 complexes and subsequent mass spectrometry analysis of the interacting proteins identified PARP1 as a DDB2associated factor in human cells (Pines et al., 2012). This interaction was dependent on UV irradiation and promoted the synthesis of poly(ADP-ribose; PAR) chains in chromatin with UV-induced lesions. In DDB2-deficient cells, there was substantially less PAR immunofluorescence at UV damaged sites compared to wildtype (Pines et al., 2012). The poly(ADP-ribosyl)ation recruited the SWI/SNF chromatin remodeler ALC1 to sites of UV-induced DNA lesions. Knockdown of ALC1 using shRNA resulted in UV-sensitive cells that had deficient repair of CPDs and 6-4PPs, indicating that ALC1 activity is critical to the GGR/NER pathway (Pines et al., 2012; Table 1).

Chromatin remodeling by INO80 is also implicated in NER (Table 1). Yeast ino80 $\Delta$ mutants and mammalian cells with RNAi knockdown of Ino80 are UV sensitive (Shen et al., 2000; Wu et al., 2007). In yeast, UV-induced recruitment of Ino80 to chromatin occurs through interactions with the Rad4-Rad23 NER damage recognition complex (Sarkar et al., 2010). In mammals, Ino80 is recruited to UV-damaged chromatin, and deletion of two INO80 complex subunits, INO80 and ARP5, resulted in defective repair of UV lesions (Jiang et al., 2010). In addition, INO80-deficient cells failed to recruit the NER factors XPC and XPA, suggesting that INO80 chromatin remodeling may be necessary for lesion 
recognition and incision (Jiang et al., 2010). The links between Ino80 and NER in both yeast and mammalian systems, the UV repair defects, and the direct interactions with NER factors all support the conclusion that Ino80 is another chromatin remodeler with an important role in the NER pathway.

\section{REMODELING IN THE TCR SUBPATHWAY}

Cockayne syndrome group B and its homolog Rad26 in yeast are DNA-dependent ATPases of the SWI/SNF family of ATPdependent chromatin remodeling enzymes acting in the TCR pathway (Guzder etal., 1996; Selby and Sancar, 1997a). Both CSB and Rad26 have been shown to affect chromatin structure, based on in vitro experiments for CSB, and mutant phenotypes for Rad26 (Citterio et al., 2000; Gregory and Sweder, 2001; Table 1). In addition, both CSB and Rad26 enhance transcriptional elongation (Selby and Sancar, 1997b; Lee et al., 2001, 2002). CSB has been shown to be necessary for recruitment of repair factors to sites of damage repaired by the TCR pathway (Fousteri et al., 2006). Recently, $\operatorname{Rad} 26$ was found to promote ejection of the H2A-H2B dimer during transcription of the GAL1 gene (Malik and Bhaumik, 2012). This regulation of chromatin structure by Rad26 is critical for transcription and may be necessary for recruitment of repair factors during TCR to allow access to the DNA lesions. Future studies should directly address whether the role of $\mathrm{Rad} 26$ in promoting $\mathrm{H} 2 \mathrm{~A}-\mathrm{H} 2 \mathrm{~B}$ dimer eviction also contributes to efficient TCR.

There are some suggestions of ISWI chromatin remodeling in NER and/or TCR. In experiments using synthetic dinucleosomes containing 6-4PPs, recombinant Drosophila ACF stimulated lesion excision (Ura et al., 2001; Table 1). Also, knockdown of ISWI in human cells and C. elegans results in a modest UV sensitive phenotype (Lan et al., 2010; Lans et al., 2010; Sanchez-Molina et al., 2011). Additionally, the human ISWI isoform SMARCA5 is recruited to UV-induced DNA lesions, where it promotes binding of the TCR factor CSB and restart of damage-stalled transcription (Aydin et al., 2014). Intriguingly, purification of the human WICH complex (WSTF-SNF2H), an ISWI family complex, identified an interaction with CSB that was confirmed by co-immunoprecipitation (Cavellan et al., 2006), adding another link between ISWI and TCR. Thus, ISWI remodeling may work together with $\operatorname{Rad} 26 / \mathrm{CSB}$ to facilitate lesion repair during transcription.

\section{BASE EXCISION REPAIR (BER) WITHIN CHROMATIN}

DNA bases damaged by, for example, oxidation and alkylation, are repaired through BER. The damage repaired by BER does not significantly distort the DNA and therefore does not stall the replication or transcription machinery. The BER pathway is initiated when a glycosylase enzyme recognizes and excises the damaged base, leaving an abasic site. The abasic site is processed by apyrimidinic/apurinic endonuclease (APE), which cleaves the phosphodiester backbone, leaving a base gap. Then, DNA polymerase inserts the missing base(s) and DNA ligase seals the nick, completing the BER repair process. Although the role of chromatin structure in the BER pathway has not been investigated in depth, some links to histone modification and remodeling have been identified.
There is some recent evidence for the importance of histone modifications during BER. USP7 is a ubiquitin-specific human protease which deubiquitinates histone $\mathrm{H} 2 \mathrm{~B}$ in vitro, though it also targets non-histone substrates that include p53 (Li et al., 2002). Upon siRNA knockdown of USP7, the levels and activity of BER enzymes were not changed, but the accessibility of DNA and the repair rate of oxidative lesions were both reduced (Khoronenkova et al., 2011). These results support their model for $\mathrm{H} 2 \mathrm{~B}$ ubiquitination state affecting BER, though it will be important to address whether histone $\mathrm{H} 2 \mathrm{~B}$, or another protein substrate, is the relevant in vivo target during BER. A connection between acetylation and the BER pathway was observed in mammalian cells by co-immunoprecipitation and co-localization of thymine DNA glycosylase (TDG) and the HAT p300 (Tini et al., 2002). P300/TDG complexes are competent for histone acetylation and TDG itself is also acetylated by p300, therefore TDG may be the relevant target of p300 (Tini et al., 2002). To date, no other histone modifications have been demonstrated to affect BER and therefore this is an interesting area for further study.

Multiple in vitro studies have investigated whether BER enzymes can function properly in the context of a nucleosomecontaining template. Using uracil-containing oligonucleosome arrays, the activities of uracil DNA glycosylase (UDG), which recognizes uracil in DNA, and APE, which recognizes abasic sites, were both uninhibited, suggesting that the initial steps of BER by UDG and APE can act efficiently in intact chromatin (Nakanishi et al., 2007). However, synthesis by the polymerase functioning in BER, DNA polymerase $\beta$, was significantly reduced in the oligonucleosome array (Nakanishi et al., 2007). This inhibition was lessened upon addition of purified yeast Isw1 and Isw2, both chromatin remodelers of the ISWI family, suggesting that remodeling could be crucial for later repair events in BER within compact chromatin (Nakanishi et al., 2007; Table 1). The in vitro mechanism of BER has also been studied using an 8-oxo-7, 8-dihydroguanine (8-oxoG) lesion on reconstituted nucleosomes. Activities of murine 8-oxoguanine DNA glycosylase (OGG1), human APE, and human polymerase $\beta$ were all reduced compared to their activity on a naked DNA substrate (Menoni et al., 2007). The addition of the yeast SWI/SNF complex stimulated the activity of all three BER enzymes in the repair of the oxidative lesion in the nucleosomal array, to a level comparable to their activity on naked DNA (Table 1). This effect required SWI2/SNF2 dependent remodeling but not relocation of nucleosomes (Menoni etal., 2007). These two in vitro studies utilized different types of BER lesions in the context of a nucleosome substrate. Both concluded that chromatin remodeling promotes polymerase $\beta$ activity, however, differences were seen for the activities of the glycosylases (UDG, OGG1) and endonuclease APE on the nucleosome substrates that were used, which may be related to the lesion type or the nucleosome substrate itself. Overall, these studies both point to a role for the SWI/SNF family remodelers for efficient BER, though an in vivo role must still be established. Recently, it was shown that depletion of STH1, the ATPase subunit of RSC, results in sensitivity to MMS, and BER is considerably inhibited in cells lacking STH1 (Czaja et al., 2014). This establishes the first in vivo link between chromatin remodeling and BER. 


\section{HISTONE MODIFICATIONS AND NUCLEOSOME REMODELING DURING MISMATCH REPAIR (MMR)}

Postreplication mismatch repair (MMR) is initiated when a base mismatch escapes the DNA polymerase proofreading machinery. In human cells, MMR is regulated by histone H3-K36 trimethylation (Figure 1F). H3-K36me3 is required in vivo to recruit the heterodimer MSH2-MSH6 (MutS $\alpha$ ) to chromatin through the Pro-Trp-Trp-Pro (PWWP) domain of MSH6, a domain that specifically interacts with H3-K36me3 (Li et al., 2013). Since H3K36me3 is abundant during G1 and early S phase, it is thought that this ensures the enrichment of MutS $\alpha$ on DNA during the period when mismatches are likely to arise. Cells that lack the H3-K36 trimethyltransferase SETD2 have altered MSH6 localization and a mutator phenotype, but are not defective in MMR in vitro ( $\mathrm{Li}$ et al., 2013). Whether additional histone modifications are involved in MMR is as yet unknown; good candidates may be those associated with the progression of DNA replication, such as H3-K56 (Kadyrova et al., 2013).

Because nucleosomes become disassembled in front of a replication fork, newly replicated DNA is relatively nucleosomepoor and MMR may not need robust chromatin remodeling to effectively compete with nucleosomes. However, fully formed nucleosomes have been observed about $250 \mathrm{bp}$ from a replication fork, and there are intermediates in the assembly process in the region in between (Sogo et al., 1986; Jackson, 1988). Therefore, the MMR machinery is likely to encounter some completely formed nucleosomes in addition to nucleosome intermediates. There is some evidence for interaction between MMR factors and the histone $\mathrm{H} 3-\mathrm{H} 4$ chaperone chromatin assembly factor 1 (CAF-1). Mismatch correction reactions with HeLa cell extracts demonstrated that replication error correction occurs on DNA that is packaged into nucleosomes by CAF-1 (Kadyrova et al., 2011). However, in a combined in vitro MMR and nucleosome assembly assay, a mismatch in a nicked plasmid substrate delayed loading of nucleosomes in a human cell extract (Schöpf et al., 2012), suggesting that MMR interferes with nucleosome assembly. The balance between MMR and chromatin reassembly may be regulated by a physical interaction between MutS $\alpha$, specifically MSH6, and the p150 subunit of CAF-1 (Schöpf et al., 2012).

In addition to these interactions between MMR and chromatin assembly factors, passive chromatin remodeling assists the MMR process. Using in vitro experiments with reconstituted nucleosomes and purified human proteins, the MMR initiation heterodimer MutS $\alpha$ disassembles nucleosomes (Javaid et al., 2009). Nucleosome remodeling by MutS $\alpha$ required a mismatch and translocation of the complex as a sliding clamp along the DNA (Javaid etal., 2009). The nucleosome remodeling function required ATP binding but not hydrolysis, suggesting that the remodeling function is passive. Histone $\mathrm{H} 3$ acetylation or an $\mathrm{H} 3$ acetylation mimic (H3-K115Ac, H3-K122Ac, H3-K56Q), enhanced the remodeling function of MutS $\alpha$ (Javaid et al., 2009). Additionally, phosphorylation of histone H3-T118 enhanced nucleosome disassembly by MutS $\alpha$ by 25 -fold in vitro (North et al., 2011). However, no in vivo investigation has been done yet to support a role for $\mathrm{H} 3$ phosphorylation or acetylation in MMR. There is also evidence that passive MutS $\alpha$-dependent nucleosome disassembly may not be sufficient, as human MutS $\alpha$ bound poorly to a substrate with a mismatch within a nucleosome ( $\mathrm{Li}$ et al., 2009). In addition, nucleosomes blocked ATP-induced sliding of MutS $\alpha$ along the DNA when there was a mismatch between two nucleosomes ( $\mathrm{Li}$ et al., 2009). Overall, these findings indicate that nucleosomes likely inhibit the MMR process to some degree, and active remodeling may yet be found to play a role in MMR.

\section{CONCLUDING REMARKS}

The interplay between histone modifications and DNA repair likely creates a diverse array of cellular responses to DNA damage based on the type of lesion and the preferred pathway of repair for a particular lesion. $\gamma \mathrm{H} 2 \mathrm{AX}$ is the first detectable histone modification in response to DSBs, but it appears to be a general initial modification, acting as a broad signal of DNA damage, activating signaling cascades in response to stalled forks, gaps, DNA structures, and UV lesions, as well as DSBs. The subsequent, downstream histone modifications may guide repair to the appropriate pathway based on lesion type.

A major unanswered question for many of the histone modifications summarized here is their mechanism of action. Do histone marks recruit specific repair factors or remodelers via direct interaction, or change local chromatin accessibility in a more general way, or a combination of both? Several examples of direct interactions exist, for example Arp4, a subunit of INO80, SWR1, and NuA4 complexes, binds specifically to yeast H2A phosphorylated at Ser129 (Downs et al., 2004). In mammalian cells, the repair mediator MDC1 binds directly to $\gamma \mathrm{H} 2 \mathrm{AX}$ via tandem BRCT domains (Uziel et al., 2003; Lukas et al., 2004; Stucki et al., 2005). In addition, other roles for modifications can also be envisioned, such as repositioning of the damaged area to another nuclear compartment to direct appropriate repair (Dion and Gasser, 2013).

Specific combinations of histone modifications may also be important to differentially favor the recruitment of particular repair factors. Depending on the interaction of the repair proteins with the histone modifications, progressive histone modifications after DNA damage could influence repair pathway choice or progression. One example of this during DSB repair in human cells is Tyr142 on H2AX, which is phosphorylated in the absence of DNA damage by the WSTF kinase (Xiao et al., 2009). However, upon DNA damage and phosphorylation of H2AX at Ser139, Tyr142 is dephosphorylated by the Eyal and Eya3 tyrosine phosphatases (Cook et al., 2009). While the di-phospho $\gamma \mathrm{H} 2 \mathrm{AX}$ can be bound by the repair factor MCPH1, MDC1 only efficiently binds $\gamma \mathrm{H} 2 \mathrm{AX}$ once it is dephosphorylated at Tyr142 (Singh et al., 2012), thus directing binding of repair factors in an orderly fashion. In most cases, relatively little is understood about the order of the occurrence of the modifications depicted in Figure 1, and whether some work together to recruit factors, change chromatin structure, or signal completion of repair.

It is reasonable to expect that different lesions will also require a different chromatin environment to promote repair, and thus unique levels and types of chromatin remodeling. End resection, D-loop extension during HR, gap filling, fork restart, and repair of base lesions or mismatches could each require a certain degree of nucleosome movement or displacement. For instance, 
if a homologous template is utilized for repair, chromatin remodeling will require the movement of several nucleosomes at the targeted, homologous sequence to allow invasion into the template sequence and subsequent copying, as well as at the site of the lesion if any resection is required for repair; on the other hand, repair of base lesions or gap filling without strand invasion may not require as substantial of a remodeling process. Finally, repair resolution will require reestablishment of the chromatin state and DNA damage checkpoint recovery. Depending on the chromatin modifications that took place during repair, the disruption to the chromatin will vary and thus may require different factors to reestablish the normal chromatin state.

Some combinations of histone modifications that distinguish repair pathways from one another are summarized here, but many remain to be identified. Understanding how these histone modifications work together to contribute to repair will further our understanding of how the DNA repair machinery functions within the context of the chromatin structure. Additionally, roles for chromatin modifications in designating repair choice, orderly progression of repair, turnover of repair factors, and resolution of the damage response may be revealed.

\section{ACKNOWLEDGMENTS}

We thank the members of the Freudenreich laboratory for helpful discussions. Melissa R. Koch was supported by the Tufts TEACRS postdoctoral program (NIH IRACDA K12 award) and NSF award 1330743 to Catherine H. Freudenreich. Catherine H. Freudenreich and Nealia C. M. House acknowledge support from Tufts University Faculty and Graduate Student Research Awards, respectively, and NIH P01 GM105473.

\section{REFERENCES}

Altaf, M., Auger, A., Monnet-Saksouk, J., Brodeur, J., Piquet, S., Cramet, M., et al. (2010). NuA4-dependent acetylation of nucleosomal histones H4 and H2A directly stimulates incorporation of H2A.Z by the SWR1 complex. J. Biol. Chem. 285, 15966-15977. doi: 10.1074/jbc.M110.117069

Anand, R. P., Shah, K. A., Niu, H., Sung, P., Mirkin, S. M., and Freudenreich, C. H. (2012). Overcoming natural replication barriers: differential helicase requirements. Nucleic Acids Res. 40, 1091-1105. doi: 10.1093/nar/gkr836

Ataian, Y., and Krebs, J. E. (2006). Five repair pathways in one context: chromatin modification during DNA repair. Biochem. Cell Biol. 84, 490-504. doi: 10.1139/o06-075

Au, T. J., Rodriguez, J., Vincent, J. A., and Tsukiyama, T. (2011). ATP-dependent chromatin remodeling factors tune S phase checkpoint activity. Mol. Cell. Biol. 31, 4454-4463. doi: 10.1128/MCB.05931-11

Aydin, O. Z., Marteijn, J. A., Ribeiro-Silva, C., Rodriguez Lopez, A., Wijgers, N., Smeenk, G., et al. (2014). Human ISWI complexes are targeted by SMARCA5 ATPase and SLIDE domains to help resolve lesion-stalled transcription. Nucleic Acids Res. 42, 8473-8485. doi: 10.1093/nar/gku565

Ayrapetov, M. K., Gursoy-Yuzugullu, O., Xu, C., Xu, Y., and Price, B. D. (2014). DNA double-strand breaks promote methylation of histone $\mathrm{H} 3$ on lysine 9 and transient formation of repressive chromatin. Proc. Natl. Acad. Sci. U.S.A. 111, 9169-9174. doi: 10.1073/pnas.1403565111

Baetz, K. K., Krogan, N. J., Emili, A., Greenblatt, J., and Hieter, P. (2004). The ctf13-30/CTF13 genomic haploinsufficiency modifier screen identifies the yeast chromatin remodeling complex RSC, which is required for the establishment of sister chromatid cohesion. Mol. Cell. Biol. 24, 1232-1244. doi: 10.1128/MCB.24.3.1232-1244.2003

Baker, S. P., Phillips, J., Anderson, S., Qiu, Q., Shabanowitz, J., Smith, M. M., et al. (2010). Histone $\mathrm{H} 3$ thr 45 phosphorylation is a replication-associated post-translational modification in S. cerevisiae. Nat. Cell Biol. 12, 294-298. doi: $10.1038 /$ ncb2030
Balakumaran, B. S., Freudenreich, C. H., and Zakian, V. A. (2000). CGG/CCG repeats exhibit orientation-dependent instability and orientation-independent fragility in Saccharomyces cerevisiae. Hum. Mol. Genet. 9, 93-100. doi: 10.1093/hmg/9.1.93

Bao, Y. (2011). Chromatin response to DNA double-strand break damage. Epigenomics 3, 307-321. doi: 10.2217/epi.11.14

Bazzi, M., Mantiero, D., Trovesi, C., Lucchini, G., and Longhese, M. P. (2010). Dephosphorylation of gamma H2A by Glc7/protein phosphatase 1 promotes recovery from inhibition of DNA replication. Mol. Cell. Biol. 30, 131-145. doi: 10.1128/MCB.01000-09

Bennett, G., Papamichos-Chronakis, M., and Peterson, C. L. (2013). DNA repair choice defines a common pathway for recruitment of chromatin regulators. Nat. Commun. 4:2084. doi: 10.1038/ncomms3084

Bergink, S., Salomons, F. A., Hoogstraten, D., Groothuis, T. A., de Waard, H., Wu, J., etal. (2006). DNA damage triggers nucleotide excision repairdependent monoubiquitylation of histone H2A. Genes Dev. 20, 1343-1352. doi: 10.1101/gad.373706

Bhaskara, S., Jacques, V., Rusche, J. R., Olson, E. N., Cairns, B. R., and Chandrasekharan, M. B. (2013). Histone deacetylases 1 and 2 maintain S-phase chromatin and DNA replication fork progression. Epigenetics Chromatin 6:27. doi: 10.1186/1756-8935-6-27

Bird, A. W., Yu, D. Y., Pray-Grant, M. G., Qiu, Q., Harmon, K. E., Megee, P. C., et al. (2002). Acetylation of histone H4 by Esal is required for DNA double-strand break repair. Nature 419, 411-415. doi: 10.1038/nature01035

Boiteux, S., and Jinks-Robertson, S. (2013). DNA repair mechanisms and the bypass of DNA damage in Saccharomyces cerevisiae. Genetics 193, 1025-1064. doi: 10.1534/genetics.112.145219

Bostelman, L. J., Keller, A. M., Albrecht, A. M., Arat, A., and Thompson, J. S. (2007). Methylation of histone H3 lysine-79 by Dotlp plays multiple roles in the response to UV damage in Saccharomyces cerevisiae. DNA Repair 6, 383-395. doi: 10.1016/j.dnarep.2006.12.010

Branzei, D., and Foiani, M. (2008). Regulation of DNA repair throughout the cell cycle. Nat. Rev. Mol. Cell Biol. 9, 297-308. doi: 10.1038/nrm2351

Briggs, S. D., Bryk, M., Strahl, B. D., Cheung, W. L., Davie, J. K., Dent, S. Y., et al. (2001). Histone $\mathrm{H} 3$ lysine 4 methylation is mediated by Set1 and required for cell growth and rDNA silencing in Saccharomyces cerevisiae. Genes Dev. 15, 3286-3295. doi: 10.1101/gad.940201

Briggs, S. D., Xiao, T., Sun, Z. W., Caldwell, J. A., Shabanowitz, J., Hunt, D. F., et al. (2002). Gene silencing: trans-histone regulatory pathway in chromatin. Nature 418, 498. doi: 10.1038/nature00970

Callahan, J. L., Andrews, K. J., Zakian, V. A., and Freudenreich, C. H. (2003). Mutations in yeast replication proteins that increase CAG/CTG expansions also increase repeat fragility. Mol. Cell. Biol. 23, 7849-7860. doi: 10.1128/MCB.23.21.78497860.2003

Cavellan, E., Asp, P., Percipalle, P., and Farrants, A. K. (2006). The WSTFSNF2h chromatin remodeling complex interacts with several nuclear proteins in transcription. J. Biol. Chem. 281, 16264-16271. doi: 10.1074/jbc.M600233200

Celeste, A., Difilippantonio, S., Difilippantonio, M. J., Fernandez-Capetillo, O., Pilch, D. R., Sedelnikova, O. A., et al. (2003a). H2AX haploinsufficiency modifies genomic stability and tumor susceptibility. Cell 114, 371-383. doi: 10.1016/S0092-8674(03)00567-1

Celeste, A., Fernandez-Capetillo, O., Kruhlak, M. J., Pilch, D. R., Staudt, D. W., Lee, A., et al. (2003b). Histone H2AX phosphorylation is dispensable for the initial recognition of DNA breaks. Nat. Cell Biol. 5, 675-679. doi: 10.1038/ ncb1004

Cha, R. S., and Kleckner, N. (2002). ATR homolog Mecl promotes fork progression, thus averting breaks in replication slow zones. Science 297, 602-606. doi: 10.1126/science.1071398

Chailleux, C., Tyteca, S., Papin, C., Boudsocq, F., Puget, N., Courilleau, C., et al. (2010). Physical interaction between the histone acetyl transferase Tip60 and the DNA double-strand breaks sensor MRN complex. Biochem. J. 426, 365-371. doi: 10.1042/BJ20091329

Chaudhuri, S., Wyrick, J. J., and Smerdon, M. J. (2009). Histone H3 Lys79 methylation is required for efficient nucleotide excision repair in a silenced locus of Saccharomyces cerevisiae. Nucleic Acids Res. 37, 1690-1700. doi: 10.1093/nar/gkp003

Chen, C. C., Carson, J. J., Feser, J., Tamburini, B., Zabaronick, S., Linger, J., et al. (2008). Acetylated lysine 56 on histone H3 drives chromatin assembly 
after repair and signals for the completion of repair. Cell 134, 231-243. doi: 10.1016/j.cell.2008.06.035

Cheung, W. L., Turner, F. B., Krishnamoorthy, T., Wolner, B., Ahn, S. H., Foley, M., et al. (2005). Phosphorylation of histone H4 serine 1 during DNA damage requires casein kinase II in S. cerevisiae. Curr. Biol. 15, 656-660. doi: 10.1016/j.cub.2005.02.049

Chowdhury, D., Keogh, M. C., Ishii, H., Peterson, C. L., Buratowski, S., and Lieberman, J. (2005). Gamma-H2AX dephosphorylation by protein phosphatase 2A facilitates DNA double-strand break repair. Mol. Cell 20, 801-809. doi: 10.1016/j.molcel.2005.10.003

Chowdhury, D., Xu, X., Zhong, X., Ahmed, F., Zhong, J., Liao, J., et al. (2008). A PP4-phosphatase complex dephosphorylates gamma-H2AX generated during DNA replication. Mol. Cell 31, 33-46. doi: 10.1016/j.molcel.2008.05.016

Chubb, J. E., and Rea, S. (2010). Core and linker histone modifications involved in the DNA damage response. Subcell. Biochem. 50, 17-42. doi: 10.1007/978-90481-3471-7_2

Citterio, E., Van Den Boom, V., Schnitzler, G., Kanaar, R., Bonte, E., Kingston, R. E. et al. (2000). ATP-dependent chromatin remodeling by the cockayne syndrome B DNA repair-transcription-coupling factor. Mol. Cell. Biol. 20, 7643-7653. doi: 10.1128/MCB.20.20.7643-7653.2000

Cobb, J. A., Schleker, T., Rojas, V., Bjergbaek, L., Tercero, J. A., and Gasser, S. M. (2005). Replisome instability, fork collapse, and gross chromosomal rearrangements arise synergistically from Mecl kinase and RecQ helicase mutations. Genes Dev. 19, 3055-3069. doi: 10.1101/gad.361805

Conde, F., Refolio, E., Cordon-Preciado, V., Cortes-Ledesma, F., Aragon, L., Aguilera A., et al. (2009). The Dot1 histone methyltransferase and the Rad9 checkpoint adaptor contribute to cohesin-dependent double-strand break repair by sister chromatid recombination in Saccharomyces cerevisiae. Genetics 182, 437-446. doi: 10.1534/genetics.109.101899

Cook, P. J., Ju, B. G., Telese, F., Wang, X., Glass, C. K., and Rosenfeld, M. G. (2009). Tyrosine dephosphorylation of H2AX modulates apoptosis and survival decisions. Nature 458, 591-596. doi: 10.1038/nature07849

Czaja, W., Mao, P., and Smerdon, M. J. (2014). Chromatin remodeling complex RSC promotes base excision repair in chromatin of Saccharomyces cerevisiae. DNA Repair 16, 35-43. doi: 10.1016/j.dnarep.2014.01.002

Dion, V., and Gasser, S. M. (2013). Chromatin movement in the maintenance of genome stability. Cell 152, 1355-1364. doi: 10.1016/j.cell.2013.02.010

Doil, C., Mailand, N., Bekker-Jensen, S., Menard, P., Larsen, D. H., Pepperkok, R., et al. (2009). RNF168 binds and amplifies ubiquitin conjugates on damaged chromosomes to allow accumulation of repair proteins. Cell 136, 435-446. doi: 10.1016/j.cell.2008.12.041

Dover, J., Schneider, J., Tawiah-Boateng, M. A., Wood, A., Dean, K., Johnston, M., et al. (2002). Methylation of histone H3 by COMPASS requires ubiquitination of histone H2B by Rad6. J. Biol. Chem. 277, 28368-28371. doi: 10.1074/jbc.C200348200

Downs, J. A., Allard, S., Jobin-Robitaille, O., Javaheri, A., Auger, A., Bouchard, N., etal. (2004). Binding of chromatin-modifying activities to phosphorylated histone H2A at DNA damage sites. Mol. Cell 16, 979-990. doi: 10.1016/j.molcel.2004.12.003

Entezam, A., and Usdin, K. (2008). ATR protects the genome against CGG.CCGrepeat expansion in fragile X premutation mice. Nucleic Acids Res. 36, 1050-1056. doi: 10.1093/nar/gkm1136

Evans, M. L., Bostelman, L. J., Albrecht, A. M., Keller, A. M., Strande, N. T., and Thompson, J. S. (2008). UV sensitive mutations in histone H3 in Saccharomyces cerevisiae that alter specific K79 methylation states genetically act through distinct DNA repair pathways. Curr. Genet. 53, 259-274. doi: 10.1007/s00294-008-0182-1

Falbo, K. B., Alabert, C., Katou, Y., Wu, S., Han, J., Wehr, T., et al. (2009). Involvement of a chromatin remodeling complex in damage tolerance during DNA replication. Nat. Struct. Mol. Biol. 16, 1167-1172. doi: 10.1038/nsmb.1686

Faucher, D., and Wellinger, R. J. (2010). Methylated H3K4, a transcription-associated histone modification, is involved in the DNA damage response pathway. PLoS Genet. 6:e1001082. doi: 10.1371/journal.pgen.1001082

Fousteri, M., Vermeulen, W., van Zeeland, A. A., and Mullenders, L. H. (2006). Cockayne syndrome A and B proteins differentially regulate recruitment of chromatin remodeling and repair factors to stalled RNA polymerase II in vivo. $\mathrm{Mol}$. Cell 23, 471-482. doi: 10.1016/j.molcel.2006.06.029

Freudenreich, C. H. (2007). Chromosome fragility: molecular mechanisms and cellular consequences. Front. Biosci. 12:4911-4924. doi: 10.2741/2437
Freudenreich, C. H., Kantrow, S. M., and Zakian, V. A. (1998). Expansion and length-dependent fragility of CTG repeats in yeast. Science 279, 853-856. doi: 10.1126/science.279.5352.853

Fuchs, S. M., Laribee, R. N., and Strahl, B. D. (2009). Protein modifications in transcription elongation. Biochim. Biophys. Acta 1789, 26-36. doi: 10.1016/j.bbagrm.2008.07.008

Game, J. C., and Chernikova, S. B. (2009). The role of RAD6 in recombinational repair, checkpoints and meiosis via histone modification. DNA Repair 8, 470-482. doi: 10.1016/j.dnarep.2009.01.007

Game, J. C., Williamson, M. S., and Baccari, C. (2005). X-ray survival characteristics and genetic analysis for nine Saccharomyces deletion mutants that show altered radiation sensitivity. Genetics 169, 51-63. doi: 10.1534/genetics.104.028613

Game, J. C., Williamson, M. S., Spicakova, T., and Brown, J. M. (2006). The RAD6/BRE1 histone modification pathway in Saccharomyces confers radiation resistance through a RAD51-dependent process that is independent of RAD18. Genetics 173, 1951-1968. doi: 10.1534/genetics.106.057794

Gannon, A. M., Frizzell, A., Healy, E., and Lahue, R. S. (2012). MutS $\beta$ and histone deacetylase complexes promote expansions of trinucleotide repeats in human cells. Nucleic Acids Res. 40, 10324-10333. doi: 10.1093/nar/gks810

Giannattasio, M., Lazzaro, F., Plevani, P., and Muzi-Falconi, M. (2005). The DNA damage checkpoint response requires histone $\mathrm{H} 2 \mathrm{~B}$ ubiquitination by Rad6-Brel and H3 methylation by Dot1. J. Biol. Chem. 280, 9879-9886. doi: 10.1074/jbc.M414453200

Gong, F., Fahy, D., and Smerdon, M. J. (2006). Rad4-Rad23 interaction with SWI/SNF links ATP-dependent chromatin remodeling with nucleotide excision repair. Nat. Struct. Mol. Biol. 13, 902-907. doi: 10.1038/nsmb1152

Gottlieb, T. M., and Jackson, S. P. (1993). The DNA-dependent protein kinase: requirement for DNA ends and association with ku antigen. Cell 72, 131-142. doi: 10.1016/0092-8674(93)90057-W

Greenberg, R. A. (2011). Histone tails: directing the chromatin response to DNA damage. FEBS Lett. 585, 2883-2890. doi: 10.1016/j.febslet.2011.05.037

Gregory, S. M., and Sweder, K. S. (2001). Deletion of the CSB homolog, RAD26, yields spt(-) strains with proficient transcription-coupled repair. Nucleic Acids Res. 29, 3080-3086. doi: 10.1093/nar/29.14.3080

Grenon, M., Costelloe, T., Jimeno, S., O’Shaughnessy, A., Fitzgerald, J., Zgheib, O., et al. (2007). Docking onto chromatin via the Saccharomyces cerevisiae Rad9 tudor domain. Yeast 24, 105-119. doi: 10.1002/yea.1441

Guo, R., Chen, J., Mitchell, D. L., and Johnson, D. G. (2011). GCN5 and E2F1 stimulate nucleotide excision repair by promoting $\mathrm{H} 3 \mathrm{~K} 9$ acetylation at sites of damage. Nucleic Acids Res. 39, 1390-1397. doi: 10.1093/nar/gkq983

Guzder, S. N., Habraken, Y., Sung, P., Prakash, L., and Prakash, S. (1996). RAD26, the yeast homolog of human cockayne's syndrome group B gene, encodes a DNA-dependent ATPase. J. Biol. Chem. 271, 18314-18317. doi: 10.1074/jbc.271.31.18314

Harrigan, J. A., Belotserkovskaya, R., Coates, J., Dimitrova, D. S., Polo, S. E., Bradshaw, C. R., et al. (2011). Replication stress induces 53BP1-containing OPT domains in G1 cells. J. Cell Biol. 193, 97-108. doi: 10.1083/jcb.201011083

Hartlerode, A. J., Guan, Y., Rajendran, A., Ura, K., Schotta, G., Xie, A., et al. (2012). Impact of histone $\mathrm{H} 4$ lysine 20 methylation on 53BP1 responses to chromosomal double strand breaks. PLoS ONE 7:e49211. doi: 10.1371/journal.pone.0049211

Hashimoto, Y., Ray Chaudhuri, A., Lopes, M., and Costanzo, V. (2010). Rad51 protects nascent DNA from Mrel1-dependent degradation and promotes continuous DNA synthesis. Nat. Struct. Mol. Biol. 17, 1305-1311. doi: 10.1038/nsmb.1927

House, N., Yang, J., Walsh, S., Moy, J., Freudenreich, C. F. (2014). NuA4 initiates dynamic histone $\mathrm{H} 4$ acetylation to promote high-fidelity sister chromatid recombination at post-replication gaps. Mol. Cell doi: 10.1016/j.molcel.2014.07.007 [Epub ahead of print].

Hsiao, K. Y., and Mizzen, C. A. (2013). Histone H4 deacetylation facilitates 53BP1 DNA damage signaling and double-strand break repair. J. Mol. Cell Biol. 5, 157165. doi: 10.1093/jmcb/mjs066

Huen, M. S., Grant, R., Manke, I., Minn, K., Yu, X., Yaffe, M. B., et al. (2007). RNF8 transduces the DNA-damage signal via histone ubiquitylation and checkpoint protein assembly. Cell 131, 901-914. doi: 10.1016/j.cell.2007.09.041

Humpal, S. E., Robinson, D. A., and Krebs, J. E. (2009). Marks to stop the clock: histone modifications and checkpoint regulation in the DNA damage response. Biochem. Cell Biol. 87, 243-253. doi: 10.1139/O08-109

Hur, S. K., Park, E. J., Han, J. E., Kim, Y. A., Kim, J. D., Kang, D., et al. (2010). Roles of human INO80 chromatin remodeling enzyme in DNA replication and 
chromosome segregation suppress genome instability. Cell. Mol. Life Sci. 67, 2283-2296. doi: 10.1007/s00018-010-0337-3

Ikura, T., Ogryzko, V. V., Grigoriev, M., Groisman, R., Wang, J., Horikoshi, M., et al. (2000). Involvement of the TIP60 histone acetylase complex in DNA repair and apoptosis. Cell 102, 463-473. doi: 10.1016/S0092-8674(00)00051-9

Ikura, T., Tashiro, S., Kakino, A., Shima, H., Jacob, N., Amunugama, R., et al. (2007). DNA damage-dependent acetylation and ubiquitination of $\mathrm{H} 2 \mathrm{AX}$ enhances chromatin dynamics. Mol. Cell. Biol. 27, 7028-7040. doi: 10.1128/MCB.00579-07

Jackson, V. (1988). Deposition of newly synthesized histones: hybrid nucleosomes are not tandemly arranged on daughter DNA strands. Biochemistry 27, 2109 2120. doi: 10.1021/bi00406a044

Jankowski, C., Nasar, F., and Nag, D. K. (2000). Meiotic instability of CAG repeat tracts occurs by double-strand break repair in yeast. Proc. Natl. Acad. Sci. U.S.A. 97, 2134-2139. doi: 10.1073/pnas.040460297

Javaid, S., Manohar, M., Punja, N., Mooney, A., Ottesen, J. J., Poirier, M. G., et al. (2009). Nucleosome remodeling by hMSH2-hMSH6. Mol. Cell 36, 1086-1094 doi: 10.1016/j.molcel.2009.12.010

Jiang, Y., Wang, X., Bao, S., Guo, R., Johnson, D. G., Shen, X., et al. (2010) INO80 chromatin remodeling complex promotes the removal of UV lesions by the nucleotide excision repair pathway. Proc. Natl. Acad. Sci. U.S.A. 107, 17274-17279. doi: 10.1073/pnas. 1008388107

Kadyrova, L. Y., Blanko, E. R., and Kadyrov, F. A. (2011). CAF-I-dependent control of degradation of the discontinuous strands during mismatch repair. Proc. Natl. Acad. Sci. U.S.A. 108, 2753-2758. doi: 10.1073/pnas.1015914108

Kadyrova, L. Y., Mertz, T. M., Zhang, Y., Northam, M. R., Sheng, Z., Lobachev, K. S., et al. (2013). A reversible histone H3 acetylation cooperates with mismatch repair and replicative polymerases in maintaining genome stability. PLoS Genet. 9:e1003899. doi: 10.1371/journal.pgen.1003899

Kapetanaki, M. G., Guerrero-Santoro, J., Bisi, D. C., Hsieh, C. L., Rapic-Otrin, V., and Levine, A. S. (2006). The DDB1-CUL4ADDB2 ubiquitin ligase is deficient in xeroderma pigmentosum group E and targets histone $\mathrm{H} 2 \mathrm{~A}$ at UV-damaged DNA sites. Proc. Natl. Acad. Sci. U.S.A. 103, 2588-2593. doi: 10.1073/pnas.0511160103

Kent, N. A., Chambers, A. L., and Downs, J. A. (2007). Dual chromatin remodeling roles for RSC during DNA double strand break induction and repair at the yeast MAT locus. J. Biol. Chem. 282, 27693-27701. doi: 10.1074/jbc.M704707200

Keogh, M. C., Kim, J. A., Downey, M., Fillingham, J., Chowdhury, D., Harrison, J. C., etal. (2006). A phosphatase complex that dephosphorylates gammaH2AX regulates DNA damage checkpoint recovery. Nature 439, 497-501. doi: $10.1038 /$ nature 04384

Kerrest, A., Anand, R. P., Sundararajan, R., Bermejo, R., Liberi, G., Dujon, B., et al. (2009). SRS2 and SGS1 prevent chromosomal breaks and stabilize triplet repeats by restraining recombination. Nat. Struct. Mol. Biol. 16, 159-167. doi: $10.1038 /$ nsmb. 1544

Khoronenkova, S. V., Dianova, I. I., Parsons, J. L., and Dianov, G. L. (2011). USP7/HAUSP stimulates repair of oxidative DNA lesions. Nucleic Acids Res. 39, 2604-2609. doi: 10.1093/nar/gkq1210

Kikuchi, H., Kuribayashi, F., Imajoh-Ohmi, S., Nishitoh, H., Takami, Y., and Nakayama, T. (2012). GCN5 protects vertebrate cells against UV-irradiation via controlling gene expression of DNA polymerase eta. J. Biol. Chem. 287, 39842-39849. doi: 10.1074/jbc.M112.406389

Kim, H. S., Rhee, D. K., and Jang, Y. K. (2008). Methylations of histone H3 lysine 9 and lysine 36 are functionally linked to DNA replication checkpoint control in fission yeast. Biochem. Biophys. Res. Commun. 368, 419-425. doi: 10.1016/j.bbrc.2008.01.104

Kim, J. C., and Mirkin, S. M. (2013). The balancing act of DNA repeat expansions. Curr. Opin. Genet. Dev. 23, 280-288. doi: 10.1016/j.gde.2013.04.009

Kolas, N. K., Chapman, J. R., Nakada, S., Ylanko, J., Chahwan, R., Sweeney, F. D., et al. (2007). Orchestration of the DNA-damage response by the RNF8 ubiquitin ligase. Science 318, 1637-1640. doi: 10.1126/science.1150034

Krishnan, V., Chow, M. Z., Wang, Z., Zhang, L., Liu, B., Liu, X., et al. (2011). Histone H4 lysine 16 hypoacetylation is associated with defective DNA repair and premature senescence in Zmpste24-deficient mice. Proc. Natl. Acad. Sci. U.S.A. 108, 12325-12330. doi: 10.1073/pnas.1102789108

Kruhlak, M., Crouch, E. E., Orlov, M., Montano, C., Gorski, S. A., Nussenzweig, A., et al. (2007). The ATM repair pathway inhibits RNA polymerase I transcription in response to chromosome breaks. Nature 447, 730-734. doi: 10.1038/nature05842

Kumari, D., Lokanga, R., Yudkin, D., Zhao, X. N., and Usdin, K. (2012). Chromatin changes in the development and pathology of the Fragile X-associated disorders and Friedreich ataxia. Biochim. Biophys. Acta 1819, 802-810. doi: 10.1016/j.bbagrm.2011.12.009

Kumari, D., and Usdin, K. (2009). Chromatin remodeling in the noncoding repeat expansion diseases. J. Biol. Chem. 284, 7413-7417. doi: 10.1074/jbc.R80002620

Lahiri, M., Gustafson, T. L., Majors, E. R., and Freudenreich, C. H. (2004). Expanded CAG repeats activate the DNA damage checkpoint pathway. Mol. Cell 15, 287-293. doi: 10.1016/j.molcel.2004.06.034

Lan, L., Ui, A., Nakajima, S., Hatakeyama, K., Hoshi, M., Watanabe, R., et al. (2010). The ACF1 complex is required for DNA double-strand break repair in human cells. Mol. Cell 40, 976-987. doi: 10.1016/j.molcel.2010.12.003

Lans, H., Marteijn, J. A., Schumacher, B., Hoeijmakers, J. H., Jansen, G., and Vermeulen, W. (2010). Involvement of global genome repair, transcription coupled repair, and chromatin remodeling in UV DNA damage response changes during development. PLoS Genet. 6:e1000941. doi: 10.1371/journal.pgen.1000941

Lans, H., Marteijn, J. A., and Vermeulen, W. (2012). ATP-dependent chromatin remodeling in the DNA-damage response. Epigenetics Chromatin 5:4. doi: 10.1186/1756-8935-5-4

Lee, H. S., Park, J. H., Kim, S. J., Kwon, S. J., and Kwon, J. (2010). A cooperative activation loop among SWI/SNF, gamma-H2AX and $\mathrm{H} 3$ acetylation for DNA double-strand break repair. EMBO J. 29, 1434-1445. doi: 10.1038/emboj.2010.27

Lee, J. H., and Paull, T. T. (2005). ATM activation by DNA double-strand breaks through the Mrel1-Rad50-Nbs1 complex. Science 308, 551-554. doi: 10.1126/science. 1108297

Lee, S. K., Yu, S. L., Prakash, L., and Prakash, S. (2001). Requirement for yeast RAD26, a homolog of the human CSB gene, in elongation by RNA polymerase II. Mol. Cell. Biol. 21, 8651-8656. doi: 10.1128/MCB.21.24.86518656.2001

Lee, S. K., Yu, S. L., Prakash, L., and Prakash, S. (2002). Yeast RAD26, a homolog of the human CSB gene, functions independently of nucleotide excision repair and base excision repair in promoting transcription through damaged bases. Mol. Cell. Biol. 22, 4383-4389. doi: 10.1128/MCB.22.12.4383-4389.2002

Li, F., Mao, G., Tong, D., Huang, J., Gu, L., Yang, W., et al. (2013). The histone mark H3K36me3 regulates human DNA mismatch repair through its interaction with MutS $\alpha$. Cell 153, 590-600. doi: 10.1016/j.cell.2013.03.025

Li, F., Tian, L., Gu, L., and Li, G. M. (2009). Evidence that nucleosomes inhibit mismatch repair in eukaryotic cells. J. Biol. Chem. 284, 33056-33061. doi: 10.1074/jbc.M109.049874

Li, M., Chen, D., Shiloh, A., Luo, J., Nikolaev, A. Y., Qin, J., et al. (2002). Deubiquitination of $\mathrm{p} 53$ by HAUSP is an important pathway for p53 stabilization. Nature 416, 648-653. doi: 10.1038/nature737

Li, Q., Zhou, H., Wurtele, H., Davies, B., Horazdovsky, B., Verreault, A., et al. (2008). Acetylation of histone $\mathrm{H} 3$ lysine 56 regulates replication-coupled nucleosome assembly. Cell 134, 244-255. doi: 10.1016/j.cell.2008.06.018

Li, X., Corsa, C. A., Pan, P. W., Wu, L., Ferguson, D., Yu, X., et al. (2010). MOF and $\mathrm{H} 4 \mathrm{~K} 16$ acetylation play important roles in DNA damage repair by modulating recruitment of DNA damage repair protein Mdc1. Mol. Cell. Biol. 30, 5335-5347. doi: 10.1128/MCB.00350-10

Lou, Z., Minter-Dykhouse, K., Franco, S., Gostissa, M., Rivera, M. A., Celeste, A., et al. (2006). MDC1 maintains genomic stability by participating in the amplification of ATM-dependent DNA damage signals. Mol. Cell 21, 187-200. doi: 10.1016/j.molcel.2005.11.025

Lukas, C., Melander, F., Stucki, M., Falck, J., Bekker-Jensen, S., Goldberg, M., et al. (2004). Mdcl couples DNA double-strand break recognition by Nbs1 with its H2AX-dependent chromatin retention. EMBO J. 23, 2674-2683. doi: 10.1038/sj.emboj.7600269

Lukas, C., Savic, V., Bekker-Jensen, S., Doil, C., Neumann, B., Pedersen, R. S., et al. (2011). 53BP1 nuclear bodies form around DNA lesions generated by mitotic transmission of chromosomes under replication stress. Nat. Cell Biol. 13, 243253. doi: $10.1038 / \mathrm{ncb} 2201$

MacDougall, C. A., Byun, T. S., Van, C., Yee, M. C., and Cimprich, K. A. (2007). The structural determinants of checkpoint activation. Genes Dev. 21, 898-903. doi: 10.1101/gad.1522607

Mahaney, B. L., Meek, K., and Lees-Miller, S. P. (2009). Repair of ionizing radiationinduced DNA double-strand breaks by non-homologous end-joining. Biochem. J. 417, 639-650. doi: 10.1042/BJ20080413

Mailand, N., Bekker-Jensen, S., Faustrup, H., Melander, F., Bartek, J., Lukas, C., et al. (2007). RNF8 ubiquitylates histones at DNA double-strand breaks and promotes assembly of repair proteins. Cell 131, 887-900. doi: 10.1016/j.cell.2007.09.040 
Malik, S., and Bhaumik, S. R. (2012). Rad26p, a transcription-coupled repair factor, promotes the eviction and prevents the reassociation of histone $\mathrm{H} 2 \mathrm{~A}-\mathrm{H} 2 \mathrm{~B}$ dimer during transcriptional elongation in vivo. Biochemistry 51, 5873-5875. doi: 10.1021/bi3005768

Malik, S., Chaurasia, P., Lahudkar, S., Durairaj, G., Shukla, A., and Bhaumik, S. R. (2010). Rad26p, a transcription-coupled repair factor, is recruited to the site of DNA lesion in an elongating RNA polymerase II-dependent manner in vivo. Nucleic Acids Res. 38, 1461-1477. doi: 10.1093/nar/gkp1147

Marteijn, J. A., Bekker-Jensen, S., Mailand, N., Lans, H., Schwertman, P., Gourdin, A. M., et al. (2009). Nucleotide excision repair-induced H2A ubiquitination is dependent on MDC1 and RNF8 and reveals a universal DNA damage response. J. Cell Biol. 186, 835-847. doi: 10.1083/jcb.200902150

Matsumoto, M., Yaginuma, K., Igarashi, A., Imura, M., Hasegawa, M., Iwabuchi, K., et al. (2007). Perturbed gap-filling synthesis in nucleotide excision repair causes histone H2AX phosphorylation in human quiescent cells. J. Cell Sci. 120(Pt 6), 1104-1112. doi: 10.1242/jcs.03391

McMurray, C. T. (2010). Mechanisms of trinucleotide repeat instability during human development. Nat. Rev. Genet. 11, 786-799. doi: 10.1038/nrg2828

Menoni, H., Gasparutto, D., Hamiche, A., Cadet, J., Dimitrov, S., Bouvet, P., et al. (2007). ATP-dependent chromatin remodeling is required for base excision repair in conventional but not in variant H2A.bbd nucleosomes. Mol. Cell. Biol. 27, 5949-5956. doi: 10.1128/MCB.00376-07

Miller, K. M., and Jackson, S. P. (2012). Histone marks: repairing DNA breaks within the context of chromatin. Biochem. Soc. Trans. 40, 370-376. doi: 10.1042/BST20110747

Miller, K. M., Tjeertes, J. V., Coates, J., Legube, G., Polo, S. E., Britton, S., et al. (2010) Human HDAC1 and HDAC2 function in the DNA-damage response to promote DNA nonhomologous end-joining. Nat. Struct. Mol. Biol. 17, 1144-1151. doi: 10.1038/nsmb.1899

Miller, T., Krogan, N. J., Dover, J., Erdjument-Bromage, H., Tempst, P., Johnston, M., et al. (2001). COMPASS: A complex of proteins associated with a trithoraxrelated SET domain protein. Proc. Natl. Acad. Sci. U.S.A. 98, 12902-12907. doi: 10.1073/pnas.231473398

Min, J. N., Tian, Y., Xiao, Y., Wu, L., Li, L., and Chang, S. (2013). The mINO80 chromatin remodeling complex is required for efficient telomere replication and maintenance of genome stability. Cell Res. 23, 1396-1413. doi $10.1038 / \mathrm{cr} .2013 .113$

Mirkin, S. M. (2007). Expandable DNA repeats and human disease. Nature 447, 932-940. doi: 10.1038/nature05977

Morrison, A. J., Highland, J., Krogan, N. J., Arbel-Eden, A., Greenblatt, J. F., Haber, J. E., et al. (2004). INO80 and gamma-H2AX interaction links ATPdependent chromatin remodeling to DNA damage repair. Cell 119, 767-775. doi: 10.1016/j.cell.2004.11.037

Moyal, L., Lerenthal, Y., Gana-Weisz, M., Mass, G., So, S., Wang, S. Y., et al. (2011). Requirement of ATM-dependent monoubiquitylation of histone H2B for timely repair of DNA double-strand breaks. Mol. Cell 41, 529-542. doi: 10.1016/j.molcel.2011.02.015

Munoz-Galvan, S., Jimeno, S., Rothstein, R., and Aguilera, A. (2013). Histone H3K56 acetylation, Rad52, and non-DNA repair factors control double-strand break repair choice with the sister chromatid. PLoS Genet. 9:e1003237. doi: 10.1371/journal.pgen.1003237

Murr, R., Loizou, J. I., Yang, Y. G., Cuenin, C., Li, H., Wang, Z. Q., et al. (2006) Histone acetylation by trrap-Tip60 modulates loading of repair proteins and repair of DNA double-strand breaks. Nat. Cell Biol. 8, 91-99. doi: 10.1038/ ncb 1343

Nakada, S., Chen, G. I., Gingras, A. C., and Durocher, D. (2008). PP4 is a gamma $\mathrm{H} 2 \mathrm{AX}$ phosphatase required for recovery from the DNA damage checkpoint EMBO Rep. 9, 1019-1026. doi: 10.1038/embor.2008.162

Nakanishi, S., Lee, J. S., Gardner, K. E., Gardner, J. M., Takahashi, Y. H., Chandrasekharan, M. B., et al. (2009). Histone H2BK123 monoubiquitination is the critical determinant for $\mathrm{H} 3 \mathrm{~K} 4$ and $\mathrm{H} 3 \mathrm{~K} 79$ trimethylation by COMPASS and Dot 1 . J. Cell Biol. 186, 371-377. doi: 10.1083/jcb.200906005

Nakanishi, S., Prasad, R., Wilson, S. H., and Smerdon, M. (2007). Different structural states in oligonucleosomes are required for early versus late steps of base excision repair. Nucleic Acids Res. 35, 4313-4321. doi: 10.1093/nar/gkm436

Ng, H. H., Xu, R. M., Zhang, Y., and Struhl, K. (2002). Ubiquitination of histone $\mathrm{H} 2 \mathrm{~B}$ by Rad6 is required for efficient Dot1-mediated methylation of histone $\mathrm{H} 3$ lysine 79. J. Biol. Chem. 277, 34655-34657. doi: 10.1074/jbc.C200433200
Niimi, A., Chambers, A. L., Downs, J. A., and Lehmann, A. R. (2012). A role for chromatin remodellers in replication of damaged DNA. Nucleic Acids Res. 40, 7393-7403. doi: 10.1093/nar/gks453

North, J. A., Javaid, S., Ferdinand, M. B., Chatterjee, N., Picking, J. W., Shoffner, M., et al. (2011). Phosphorylation of histone H3(T118) alters nucleosome dynamics and remodeling. Nucleic Acids Res. 39, 6465-6474. doi: 10.1093/nar/gkr304

O’Driscoll, M., Ruiz-Perez, V. L., Woods, C. G., Jeggo, P. A., and Goodship, J. A. (2003). A splicing mutation affecting expression of ataxia-telangiectasia and Rad3-related protein (ATR) results in Seckel syndrome. Nat. Genet. 33, 497-501. doi: $10.1038 /$ ng1 129

Oberdoerffer, P., Michan, S., McVay, M., Mostoslavsky, R., Vann, J., Park, S. K., et al. (2008). SIRT1 redistribution on chromatin promotes genomic stability but alters gene expression during aging. Cell 135, 907-918. doi: 10.1016/j.cell.2008. 10.025

Oum, J. H., Seong, C., Kwon, Y., Ji, J. H., Sid, A., Ramakrishnan, S., et al. (2011). RSC facilitates Rad59-dependent homologous recombination between sister chromatids by promoting cohesin loading at DNA double-strand breaks. Mol. Cell. Biol. 31, 3924-3937. doi: 10.1128/MCB.01269-10

Ozeri-Galai, E., Bester, A. C., and Kerem, B. (2012). The complex basis underlying common fragile site instability in cancer. Trends Genet. 28, 295-302. doi: 10.1016/j.tig.2012.02.006

Palomera-Sanchez, Z., Bucio-Mendez, A., Valadez-Graham, V., Reynaud, E., and Zurita, M. (2010). Drosophila 553 is required to increase the levels of the dKDM4B demethylase after UV-induced DNA damage to demethylate histone H3 lysine 9. J. Biol. Chem. 285, 31370-31379. doi: 10.1074/jbc.M110.128462

Papamichos-Chronakis, M., and Peterson, C. L. (2008). The Ino80 chromatinremodeling enzyme regulates replisome function and stability. Nat. Struct. Mol. Biol. 15, 338-345. doi: 10.1038/nsmb.1413

Paull, T. T., Rogakou, E. P., Yamazaki, V., Kirchgessner, C. U., Gellert, M., and Bonner, W. M. (2000). A critical role for histone H2AX in recruitment of repair factors to nuclear foci after DNA damage. Curr. Biol. 10, 886-895. doi: 10.1016/S09609822(00)00610-2

Pearson, C. E., Tam, M., Wang, Y.-H., Montgomery, S. E., Dar, A. C., Cleary, J. D., et al. (2002). Slipped-strand DNAs formed by long $(C A G)^{\star}(C T G)$ repeats: slipped-out repeats and slip-out junctions. Nucleic Acids Res. 30, 4534-4547. doi: $10.1093 /$ nar/gkf572

Pines, A., Vrouwe, M. G., Marteijn, J. A., Typas, D., Luijsterburg, M. S., Cansoy, M., et al. (2012). PARP1 promotes nucleotide excision repair through DDB2 stabilization and recruitment of ALC1. J. Cell Biol. 199, 235-249. doi: $10.1083 /$ jcb. 201112132

Price, B. D., and D'Andrea, A. D. (2013). Chromatin remodeling at DNA doublestrand breaks. Cell 152, 1344-1354. doi: 10.1016/j.cell.2013.02.011

Ramanathan, B., and Smerdon, M. J. (1986). Changes in nuclear protein acetylation in U.V.-damaged human cells. Carcinogenesis 7, 1087-1094. doi: 10.1093/carcin/7.7.1087

Ramsey, K. L., Smith, J. J., Dasgupta, A., Maqani, N., Grant, P., and Auble, D. T. (2004). The NEF4 complex regulates Rad4 levels and utilizes Snf2/Swi2-related ATPase activity for nucleotide excision repair. Mol. Cell. Biol. 24, 6362-6378. doi: 10.1128/MCB.24.14.6362-6378.2004

Ray, A., Mir, S. N., Wani, G., Zhao, Q., Battu, A., Zhu, Q., et al. (2009). Human SNF5/INI1, a component of the human SWI/SNF chromatin remodeling complex, promotes nucleotide excision repair by influencing ATM recruitment and downstream H2AX phosphorylation. Mol. Cell. Biol. 29, 6206-6219. doi: 10.1128/MCB.00503-09

Reed, S. H. (2011). Nucleotide excision repair in chromatin: damage removal at the drop of a HAT. DNA Repair 10, 734-742. doi: 10.1016/j.dnarep.2011.04.029

Robinson, P. J., An, W., Routh, A., Martino, F., Chapman, L., Roeder, R. G., etal. (2008). $30 \mathrm{~nm}$ chromatin fibre decompaction requires both H4K16 acetylation and linker histone eviction. J. Mol. Biol. 381, 816-825. doi: 10.1016/j.jmb.2008.04.050

Rogakou, E. P., Pilch, D. R., Orr, A. H., Ivanova, V. S., and Bonner, W. M. (1998). DNA double-stranded breaks induce histone H2AX phosphorylation on serine 139. J. Biol. Chem. 273, 5858-5868. doi: 10.1074/jbc.273.10.5858

Rubbi, C. P., and Milner, J. (2003). p53 is a chromatin accessibility factor for nucleotide excision repair of DNA damage. EMBO J. 22, 975-986. doi: 10.1093/emboj/cdg082

Samadashwily, G. M., Raca, G., and Mirkin, S. M. (1997). Trinucleotide repeats affect DNA replication in vivo. Nat. Genet. 17, 298-304. doi: 10.1038/ng1197-298 
Sanchez-Molina, S., Mortusewicz, O., Bieber, B., Auer, S., Eckey, M., Leonhardt, H., et al. (2011). Role for hACF1 in the G2/M damage checkpoint. Nucleic Acids Res. 39, 8445-8456. doi: 10.1093/nar/gkr435

Sarkar, S., Kiely, R., and McHugh, P. J. (2010). The Ino80 chromatin-remodeling complex restores chromatin structure during UV DNA damage repair. J. Cell Biol. 191, 1061-1068. doi: 10.1083/jcb.201006178

Savic, V., Yin, B., Maas, N. L., Bredemeyer, A. L., Carpenter, A. C., Helmink, B. A., et al. (2009). Formation of dynamic gamma-H2AX domains along broken DNA strands is distinctly regulated by ATM and MDC1 and dependent upon H2AX densities in chromatin. Mol. Cell 34, 298-310. doi: 10.1016/j.molcel.2009.04.012

Schöpf, B., Bregenhorn, S., Quivy, J. P., Kadyrov, F. A., Almouzni, G., and Jiricny, J. (2012). Interplay between mismatch repair and chromatin assembly. Proc. Natl. Acad. Sci. U.S.A. 109, 1895-1900. doi: 10.1073/pnas.1106696109

Schwertman, P., Lagarou, A., Dekkers, D. H., Raams, A., van der Hoek, A. C., Laffeber, C., et al. (2012). UV-sensitive syndrome protein UVSSA recruits USP7 to regulate transcription-coupled repair. Nat. Genet. 44, 598-602. doi: 10.1038/ng.2230

Scully, R., and Xie, A. (2013). Double strand break repair functions of histone H2AX. Mutat. Res. 750, 5-14. doi: 10.1016/j.mrfmmm.2013.07.007

Seeber, A., Hauer, M., and Gasser, S. M. (2013). Nucleosome remodelers in double-strand break repair. Curr. Opin. Genet. Dev. 23, 174-184. doi: 10.1016/j.gde.2012.12.008

Selby, C. P., and Sancar, A. (1997a). Human transcription-repair coupling factor CSB/ERCC6 is a DNA-stimulated ATPase but is not a helicase and does not disrupt the ternary transcription complex of stalled RNA polymerase II. J. Biol Chem. 272, 1885-1890. doi: 10.1074/jbc.272.3.1885

Selby, C. P., and Sancar, A. (1997b). Cockayne syndrome group B protein enhances elongation by RNA polymerase II. Proc. Natl. Acad. Sci. U.S.A. 94, 11205-11209. doi: 10.1073/pnas.94.21.11205

Shahbazian, M. D., Zhang, K., and Grunstein, M. (2005). Histone H2B ubiquitylation controls processive methylation but not monomethylation by Dotl and Set1. Mol. Cell 19, 271-277. doi: 10.1016/j.molcel.2005.06.010

Shanbhag, N. M., Rafalska-Metcalf, I. U., Balane-Bolivar, C., Janicki, S. M., and Greenberg, R. A. (2010). ATM-dependent chromatin changes silence transcription in cis to DNA double-strand breaks. Cell 141, 970-981. doi: 10.1016/j.cell.2010.04.038

Sharma, G. G., So, S., Gupta, A., Kumar, R., Cayrou, C., Avvakumov, N., et al. (2010). MOF and histone H4 acetylation at lysine 16 are critical for DNA damage response and double-strand break repair. Mol. Cell. Biol. 30, 3582-3595. doi: 10.1128/MCB.01476-09

Shen, X., Mizuguchi, G., Hamiche, A., and Wu, C. (2000). A chromatin remodeling complex involved in transcription and DNA processing. Nature 406, 541-544. doi: $10.1038 / 35020123$

Shi, L., and Oberdoerffer, P. (2012). Chromatin dynamics in DNA double-strand break repair. Biochim. Biophys. Acta 1819, 811-819. doi: 10.1016/j.bbagrm.2012.01.002

Shim, E. Y., Hong, S. J., Oum, J. H., Yanez, Y., Zhang, Y., and Lee, S. E. (2007). RSC mobilizes nucleosomes to improve accessibility of repair machinery to the damaged chromatin. Mol. Cell. Biol. 27, 1602-1613. doi: 10.1128/MCB.01956-06

Shimada, K., Oma, Y., Schleker, T., Kugou, K., Ohta, K., Harata, M., et al. (2008). Ino80 chromatin remodeling complex promotes recovery of stalled replication forks. Curr. Biol. 18, 566-575. doi: 10.1016/j.cub.2008.03.049

Shogren-Knaak, M., Ishii, H., Sun, J. M., Pazin, M. J., Davie, J. R., and Peterson, C. L. (2006). Histone H4-K16 acetylation controls chromatin structure and protein interactions. Science 311, 844-847. doi: 10.1126/science.1124000

Shroff, R., Arbel-Eden, A., Pilch, D., Ira, G., Bonner, W. M., Petrini, J. H., et al. (2004). Distribution and dynamics of chromatin modification induced by a defined DNA double-strand break. Curr. Biol. 14, 1703-1711. doi: 10.1016/j.cub.2004.09.047

Singh, N., Basnet, H., Wiltshire, T. D., Mohammad, D. H., Thompson, J. R., Heroux, A., et al. (2012). Dual recognition of phosphoserine and phosphotyrosine in histone variant H2A.X by DNA damage response protein MCPH1. Proc. Natl. Acad. Sci. U.S.A. 109, 14381-14386. doi: 10.1073/pnas. 1212366109

Sirbu, B. M., Couch, F. B., and Cortez, D. (2012). Monitoring the spatiotemporal dynamics of proteins at replication forks and in assembled chromatin using isolation of proteins on nascent DNA. Nat. Protoc. 7, 594-605. doi: 10.1038/nprot.2012.010

Sirbu, B. M., Couch, F. B., Feigerle, J. T., Bhaskara, S., Hiebert, S. W., and Cortez, D. (2011). Analysis of protein dynamics at active, stalled, and collapsed replication forks. Genes Dev. 25, 1320-1327. doi: 10.1101/gad.2053211
Sogo, J. M., Stahl, H., Koller, T., and Knippers, R. (1986). Structure of replicating simian virus 40 minichromosomes. The replication fork, core histone segregation and terminal structures. J. Mol. Biol. 189, 189-204. doi: 10.1016/0022-2836(86)90390-6

Stiff, T., O’Driscoll, M., Rief, N., Iwabuchi, K., Lobrich, M., and Jeggo, P. A. (2004). ATM and DNA-PK function redundantly to phosphorylate H2AX after exposure to ionizing radiation. Cancer Res. 64, 2390-2396. doi: 10.1158/0008-5472.CAN03-3207

Stiff, T., Walker, S. A., Cerosaletti, K., Goodarzi, A. A., Petermann, E., Concannon, P., et al. (2006). ATR-dependent phosphorylation and activation of ATM in response to UV treatment or replication fork stalling. EMBO J. 25, 5775-5782. doi: 10.1038/sj.emboj.7601446

Stucki, M., Clapperton, J. A., Mohammad, D., Yaffe, M. B., Smerdon, S. J., and Jackson, S. P. (2005). MDC1 directly binds phosphorylated histone H2AX to regulate cellular responses to DNA double-strand breaks. Cell 123, 1213-1226. doi: 10.1016/j.cell.2005.09.038

Sundararajan, R., and Freudenreich, C. H. (2011). Expanded CAG/CTG repeat DNA induces a checkpoint response that impacts cell proliferation in Saccharomyces cerevisiae. PLoS Genet. 7:e1001339. doi: 10.1371/journal.pgen. 1001339

Sundararajan, R., Gellon, L., Zunder, R. M., and Freudenreich, C. H. (2010). Double-strand break repair pathways protect against CAG/CTG repeat expansions, contractions and repeat-mediated chromosomal fragility in Saccharomyces cerevisiae. Genetics 184, 65-77. doi: 10.1534/genetics.109.111039

Szilard, R. K., Jacques, P. E., Laramee, L., Cheng, B., Galicia, S., Bataille, A. R., et al. (2010). Systematic identification of fragile sites via genome-wide location analysis of gamma-H2AX. Nat. Struct. Mol. Biol. 17, 299-305. doi: 10.1038/ nsmb. 1754

Takahashi, Y. H., Lee, J. S., Swanson, S. K., Saraf, A., Florens, L., Washburn, M. P., et al. (2009). Regulation of H3K4 trimethylation via 40 (Spp1) of COMPASS is monoubiquitination independent: implication for a Phe/Tyr switch by the catalytic domain of Set1. Mol. Cell. Biol. 29, 3478-3486. doi: 10.1128/MCB. 00013-09

Tamburini, B. A., and Tyler, J. K. (2005). Localized histone acetylation and deacetylation triggered by the homologous recombination pathway of double-strand DNA repair. Mol. Cell. Biol. 25, 4903-4913. doi: 10.1128/MCB.25.12.49034913.2005

Tang, J., Cho, N. W., Cui, G., Manion, E. M., Shanbhag, N. M., Botuyan, M. V., et al. (2013). Acetylation limits 53BP1 association with damaged chromatin to promote homologous recombination. Nat. Struct. Mol. Biol. 20, 317-325. doi: 10.1038/nsmb.2499

Tatum, D., and Li, S. (2011). Evidence that the histone methyltransferase Dot1 mediates global genomic repair by methylating histone $\mathrm{H} 3$ on lysine 79. J. Biol. Chem. 286, 17530-17535. doi: 10.1074/jbc.M111.241570

Teng, Y., Liu, H., Gill, H. W., Yu, Y., Waters, R., and Reed, S. H. (2008). Saccharomyces cerevisiae Rad16 mediates ultraviolet-dependent histone $\mathrm{H} 3$ acetylation required for efficient global genome nucleotide-excision repair. EMBO Rep. 9, 97-102. doi: 10.1038/sj.embor.7401112

Tini, M., Benecke, A., Um, S. J., Torchia, J., Evans, R. M., and Chambon, P. (2002). Association of CBP/p300 acetylase and thymine DNA glycosylase links DNA repair and transcription. Mol. Cell 9, 265-277. doi: 10.1016/S10972765(02)00453-7

Toh, G. W., O’Shaughnessy, A. M., Jimeno, S., Dobbie, I. M., Grenon, M., Maffini, S., et al. (2006). Histone H2A phosphorylation and $\mathrm{H} 3$ methylation are required for a novel Rad9 DSB repair function following checkpoint activation. DNA Repair 5, 693-703. doi: 10.1016/j.dnarep.2006.03.005

Tsabar, M., and Haber, J. E. (2013). Chromatin modifications and chromatin remodeling during DNA repair in budding yeast. Curr. Opin. Genet. Dev. 23, 166-173. doi: 10.1016/j.gde.2012.11.015

Ura, K., Araki, M., Saeki, H., Masutani, C., Ito, T., Iwai, S., et al. (2001). ATPdependent chromatin remodeling facilitates nucleotide excision repair of UVinduced DNA lesions in synthetic dinucleosomes. EMBO J. 20, 2004-2014. doi: 10.1093/emboj/20.8.2004

Usdin, K. (2008). The biological effects of simple tandem repeats: lessons from the repeat expansion diseases. Genome Res. 18, 1011-1019. doi: 10.1101/gr.070409.107

Utley, R. T., Lacoste, N., Jobin-Robitaille, O., Allard, S., and Cote, J. (2005). Regulation of NuA4 histone acetyltransferase activity in transcription and DNA 
repair by phosphorylation of histone H4. Mol. Cell. Biol. 25, 8179-8190. doi: 10.1128/MCB.25.18.8179-8190.2005

Uziel, T., Lerenthal, Y., Moyal, L., Andegeko, Y., Mittelman, L., and Shiloh, Y. (2003). Requirement of the MRN complex for ATM activation by DNA damage. EMBO J. 22, 5612-5621. doi: 10.1093/emboj/cdg541

van Attikum, H., Fritsch, O., and Gasser, S. M. (2007). Distinct roles for SWR1 and INO80 chromatin remodeling complexes at chromosomal double-strand breaks. EMBO J. 26, 4113-4125. doi: 10.1038/sj.emboj.7601835

van Attikum, H., Fritsch, O., Hohn, B., and Gasser, S. M. (2004). Recruitment of the INO80 complex by H2A phosphorylation links ATP-dependent chromatin remodeling with DNA double-strand break repair. Cell 119, 777-788. doi: 10.1016/j.cell.2004.11.033

Vassileva, I., Yanakieva, I., Peycheva, M., Gospodinov, A., and Anachkova, B. (2014). The mammalian INO80 chromatin remodeling complex is required for replication stress recovery. Nucleic Acids Res. doi: 10.1093/nar/gku605 [Epub ahead of print].

Verhage, R., Zeeman, A. M., de Groot, N., Gleig, F., Bang, D. D., van de Putte, P., et al. (1994). The RAD7 and RAD16 genes, which are essential for pyrimidine dimer removal from the silent mating type loci, are also required for repair of the nontranscribed strand of an active gene in Saccharomyces cerevisiae. Mol. Cell. Biol. 14, 6135-6142. doi: 10.1128/MCB.14.9.6135

Vincent, J. A., Kwong, T. J., and Tsukiyama, T. (2008). ATP-dependent chromatin remodeling shapes the DNA replication landscape. Nat. Struct. Mol. Biol. 15, 477-484. doi: 10.1038/nsmb.1419

Voineagu, I., Freudenreich, C. H., and Mirkin, S. M. (2009a). Checkpoint responses to unusual structures formed by DNA repeats. Mol. Carcinog. 48, 309-318. doi: 10.1002/mc. 20512

Voineagu, I., Surka, C. F., Shishkin, A. A., Krasilnikova, M. M., and Mirkin, S. M. (2009b). Replisome stalling and stabilization at CGG repeats, which are responsible for chromosomal fragility. Nat. Struct. Mol. Biol. 16, 226-228. doi: 10.1038/nsmb. 1527

Volle, C. B., and Delaney, S. (2012). CAG/CTG repeats alter the affinity for the histone core and the positioning of DNA in the nucleosome. Biochemistry 51, 9814-9825. doi: 10.1021/bi301416v

Wakeman, T. P., Wang, Q., Feng, J., and Wang, X. F. (2012). Bat3 facilitates H3K79 dimethylation by DOT1L and promotes DNA damage-induced 53BP1 foci at G1/G2 cell-cycle phases. EMBO J. 31, 2169-2181. doi: 10.1038/emboj. 2012.50

Wang, H., Zhai, L., Xu, J., Joo, H. Y., Jackson, S., Erdjument-Bromage, H., et al. (2006). Histone H3 and H4 ubiquitylation by the CUL4-DDB-ROC1 ubiquitin ligase facilitates cellular response to DNA damage. Mol. Cell 22, 383-394. doi: 10.1016/j.molcel.2006.03.035

Wang, Y. H. (2007). Chromatin structure of repeating CTG/CAG and CGG/CCG sequences in human disease. Front. Biosci. 12:4731-4741. doi: 10.2741/2422

Wang, Y. H., Amirhaeri, S., Kang, S., Wells, R. D., and Griffith, J. D. (1994). Preferential nucleosome assembly at DNA triplet repeats from the myotonic dystrophy gene. Science 265, 669-671. doi: 10.1126/science.8036515

Wang, Y. H., and Griffith, J. (1995). Expanded CTG triplet blocks from the myotonic dystrophy gene create the strongest known natural nucleosome positioning elements. Genomics 25, 570-573. doi: 10.1016/0888-7543(95)80061-P

Ward, I. M., and Chen, J. (2001). Histone H2AX is phosphorylated in an ATRdependent manner in response to replicational stress. J. Biol. Chem. 276, 4775947762. doi: 10.1074/jbc.C100569200

Watanabe, S., Radman-Livaja, M., Rando, O. J., and Peterson, C. L. (2013). A histone acetylation switch regulates $\mathrm{H} 2 \mathrm{~A} . \mathrm{Z}$ deposition by the SWR-C remodeling enzyme. Science 340, 195-199. doi: 10.1126/science.1229758

Wells, C. E., Bhaskara, S., Stengel, K. R., Zhao, Y., Sirbu, B., Chagot, B., et al. (2013). Inhibition of histone deacetylase 3 causes replication stress in cutaneous $\mathrm{T}$ cell lymphoma. PLoS ONE 8:e68915. doi: 10.1371/journal.pone.0068915

Wu, S., Shi, Y., Mulligan, P., Gay, F., Landry, J., Liu, H., et al. (2007). A YY1-INO80 complex regulates genomic stability through homologous recombination-based repair. Nat. Struct. Mol. Biol. 14, 1165-1172. doi: 10.1038/nsmb1332
Wurtele, H., Kaiser, G. S., Bacal, J., St-Hilaire, E., Lee, E. H., Tsao, S., et al. (2012). Histone $\mathrm{H} 3$ lysine 56 acetylation and the response to DNA replication fork damage. Mol. Cell. Biol. 32, 154-172. doi: 10.1128/MCB.05415-11

Xiao, A., Li, H., Shechter, D., Ahn, S. H., Fabrizio, L. A., Erdjument-Bromage, H., et al. (2009). WSTF regulates the H2A.X DNA damage response via a novel tyrosine kinase activity. Nature 457, 57-62. doi: 10.1038/nature07668

Xie, A., Odate, S., Chandramouly, G., and Scully, R. (2010). H2AX post-translational modifications in the ionizing radiation response and homologous recombination. Cell Cycle 9, 3602-3610. doi: 10.4161/cc.9.17.12884

Xu, Y., Ayrapetov, M. K., Xu, C., Gursoy-Yuzugullu, O., Hu, Y., and Price, B. D. (2012). Histone H2A.Z controls a critical chromatin remodeling step required for DNA double-strand break repair. Mol. Cell 48, 723-733. doi: 10.1016/j.molcel.2012.09.026

Xu, Y., and Price, B. D. (2011). Chromatin dynamics and the repair of DNA double strand breaks. Cell Cycle 10, 261-267. doi: 10.4161/cc.10.2.14543

Xu, Y., Sun, Y., Jiang, X., Ayrapetov, M. K., Moskwa, P., Yang, S., et al. (2010). The p400 ATPase regulates nucleosome stability and chromatin ubiquitination during DNA repair. J. Cell Biol. 191, 31-43. doi: 10.1083/jcb.201001160

Yang, J. H., and Freudenreich, C. H. (2010). The Rtt109 histone acetyltransferase facilitates error-free replication to prevent CAG/CTG repeat contractions. DNA Repair 9, 414-420. doi: 10.1016/j.dnarep.2009.12.022

Yu, S., Teng, Y., Waters, R., and Reed, S. H. (2011). How chromatin is remodeled during DNA repair of UV-induced DNA damage in Saccharomyces cerevisiae. PLoS Genet. 7:e1002124. doi: 10.1371/journal.pgen.1002124

Yu, Y., Deng, Y., Reed, S. H., Millar, C. B., and Waters, R. (2013). Histone variant Htzl promotes histone $\mathrm{H} 3$ acetylation to enhance nucleotide excision repair in Htz1 nucleosomes. Nucleic Acids Res. 41, 9006-9029. doi: 10.1093/nar/gkt688

Yu, Y., Teng, Y., Liu, H., Reed, S. H., and Waters, R. (2005). UV irradiation stimulates histone acetylation and chromatin remodeling at a repressed yeast locus. Proc. Natl. Acad. Sci. U.S.A. 102, 8650-8655. doi: 10.1073/pnas.0501458102

Zhang, H., and Freudenreich, C. H. (2007). An AT-rich sequence in human common fragile site FRA16D causes fork stalling and chromosome breakage in S. cerevisiae. Mol. Cell 27, 367-379. doi: 10.1016/j.molcel.2007.06.012

Zhang, L., Zhang, Q., Jones, K., Patel, M., and Gong, F. (2009). The chromatin remodeling factor BRG1 stimulates nucleotide excision repair by facilitating recruitment of XPC to sites of DNA damage. Cell Cycle 8, 3953-3959. doi: 10.4161/cc.8.23.10115

Zhao, Q., Wang, Q. E., Ray, A., Wani, G., Han, C., Milum, K., et al. (2009). Modulation of nucleotide excision repair by mammalian SWI/SNF chromatin-remodeling complex. J. Biol. Chem. 284, 30424-30432. doi: 10.1074/jbc.M109.044982

Zhu, Q., and Wani, A. A. (2010). Histone modifications: crucial elements for damage response and chromatin restoration. J. Cell. Physiol. 223, 283-288. doi: $10.1002 /$ jcp. 22060

Conflict of Interest Statement: The authors declare that the research was conducted in the absence of any commercial or financial relationships that could be construed as a potential conflict of interest.

Received: 13 September 2013; accepted: 08 August 2014; published online: 05 September 2014.

Citation: House NCM, Koch MR and Freudenreich CH (2014) Chromatin modifications and DNA repair: beyond double-strand breaks. Front. Genet. 4:296. doi: 10.3389/fgene.2014.00296

This article was submitted to Cancer Genetics, a section of the journal Frontiers in Genetics.

Copyright (c) 2014 House, Koch and Freudenreich. This is an open-access article distributed under the terms of the Creative Commons Attribution License (CC BY). The use, distribution or reproduction in other forums is permitted, provided the original author(s) or licensor are credited and that the original publication in this journal is cited, in accordance with accepted academic practice. No use, distribution or reproduction is permitted which does not comply with these terms. 